\title{
A New Platform for the Determination of Air-Sea Fluxes (OCARINA): Overview and First Results
}

\author{
D. Bourras, ${ }^{*}$ H. Branger, ${ }^{+}$G. Reverdin, ${ }^{*}$ L. MAriÉ,${ }^{@}$ R. CAMbra, ${ }^{*}$ \\ L. Baggio, ${ }^{*}$ C. CaudouX, ${ }^{*}$ G. CAudal, ${ }^{*}$ S. Morisset, ${ }^{*}$ N. Geyskens, ${ }^{*}$ \\ A. WEILL, ${ }^{*}$ AND D. HAUSER* \\ * LATMOS, Guyancourt, France \\ ${ }^{+}$Aix Marseille Université, CNRS, Marseille, France \\ ${ }^{\text {\# LOCEAN, Paris, France }}$ \\ ${ }^{\circledR}$ Ifremer, LPO, Plouzané, France \\ \& Division Technique, INSU, Meudon, France
}

(Manuscript received 1 March 2013, in final form 14 January 2014)

\begin{abstract}
The present paper describes a new type of floating platform that was specifically designed for estimating airsea fluxes, investigating turbulence characteristics in the atmospheric surface boundary layer, and studying wind-wave interactions. With its design, it can be deployed in the open ocean or in shallow-water areas. The system is designed to be used from a research vessel. It can operate for $\sim 10 \mathrm{~h}$ as a drifting wave rider and $3 \mathrm{~h}$ under power. Turbulence and meteorological instrument packages are placed at a low altitude (1-1.5 m). It was deployed for validation purposes during the Front de Marée, Variabilité (FROMVAR), 2011 experiment off the west coast of Brittany, France. Wind friction velocity and surface turbulent buoyancy flux were estimated using eddy covariance, spectral, bulk, and profile methods. The comparisons of the four methods show a reasonable agreement except for the spectral buoyancy flux. This suggests that the platform design is correct. Also, the wind measured at a fixed height above the sea shows spectral coherence with wave heights, such that wind and swell are in phase, with the largest wind values on top of swell crests. This result in qualitative agreement with current model predictions supports the capability of the Ocean Coupled to Atmosphere, Research at the Interface with a Novel Autonomous platform (OCARINA) to investigate wind-swell interactions.
\end{abstract}

\section{Introduction}

Air-sea fluxes of momentum and heat, atmospheric turbulence in the surface atmospheric boundary layer, and wind-wave interactions are key characteristics that are needed to validate and improve dynamical models of the atmosphere, the upper ocean, and waves.

There remains a need to better parameterize the fluxdrag relation as a function of sea state (e.g., Donelan et al. 1993, 1997), the determination of the so-called wind input function (e.g., Donelan et al. 2005), and to improve the Kolmogorov (1941) and Monin and Obukhov (1954) theories in stable boundary layers (e.g., Weill et al. 2003) or in the presence of swell (Smedman et al. 2009).

Corresponding author address: Denis Bourras, LATMOS, Quartier des Garennes, 11 Boulevard d'Alembert, 78280 Guyancourt, France.

E-mail: denis.bourras@latmos.ipsl.fr
There are three main methods for estimating air-sea turbulent fluxes, namely, the eddy covariance (EC) method (e.g., Katsaros et al. 1993; Anctil et al. 1994; Edson et al. 1998), the spectral method or inertial dissipation (ID) method (Edson et al. 1991), and the similarity or bulk method (e.g., Liu et al. 1979; Fairall et al. 2003).

An experimental determination of air-sea turbulent exchanges has to fulfill four different requirements: 1) using reliable and accurate instruments and recording a complete set of variables; 2) using a measurement platform that has the least possible impact on the quality of measurement data; 3 ) using instruments as close as possible to the sea surface, that is, not too far from the mean water level; and 4) having a correct operating strategy. Although these rules are purely technical and operational, they can affect substantially the overall quality of collected data. Therefore, it is necessary to optimize not only the measurement instruments but also the measurement strategy and the platforms themselves. 
The second, third, and fourth requirements are strongly conditioned by the platform used, which until now has been either a fixed platform, a towed platform (e.g., Edson et al. 1998), a research ship (e.g., Katsaros et al. 1993; Christensen et al. 2013), a floating platform, or a buoy (Anctil et al. 1994; Weller et al. 2012; Graber et al. 2000). Hereinafter, we attempt to briefly review the advantages and limitations of these platforms.

Fixed platforms such as the Woods Hole Oceanographic Institution (WHOI) Martha's Vineyard platform (Edson et al. 2007) and the Black Sea platform (e.g., Soloviev and Kudryavtsev 2010) produce continuous sampling at the same location for several days to several years, which is of invaluable interest for the study of air-sea interactions. However, possible limitations are aerodynamic distortion, which largely depends on wind direction, and the fact that most of them are not in open sea conditions, in which case the results found with fixed platforms might be specific to the conditions associated with their geographic location.

Towed platforms, the use of which was pioneered by Katsaros (1980), are helpful for sampling small-scale variations of the sea surface temperature (SST) and of the sea surface salinity (SSS), for example. However, they have limitations for wave, downwelling radiation, and atmospheric turbulence measurements, because the apparatus naturally places itself in the disturbed atmospheric wake or in the bow wave of the ship. The proximity of the ship might affect radiation data because of its color and its thermal radiation.

Quality air-sea flux data can be collected in the open ocean with a research vessel $(\mathrm{R} / \mathrm{V})$ or a floating platform, such as the Floating Instrument Platform (FLIP; e.g., Miller et al. 2008). Unfortunately, such platforms are difficult to operate and ship cruises are expensive and thus infrequent. In spite of this, the use of R/Vs is by far the most convenient way to document flux variations in a large area, because $\mathrm{R} / \mathrm{Vs}$ can cruise for up to several months. The main limitation of R/Vs is that they are affected by aerodynamic distortion of bulk quantities, but probably also at turbulent scales (Bourras et al. 2009). Note that data may also be affected by thermal effects (Berry et al. 2004). The aerodynamic distortion effect may have a large impact on the accuracy of flux estimates, because wind data are affected as a function of the shape of the ship, the location of the instruments on the ship, and the angle between the ship and the relative wind (Yelland et al. 2002). In addition, due to their large weight and dimension, most R/Vs have a large spectral motion peak in the same frequency range as waves and turbulence production $(0.01-1 \mathrm{~Hz})$, which is problematic for applying the EC method, for example. Other issues include the height of measurement, which may be considered as too far from the air-sea interface ( +7 to +17 and $-3 \mathrm{~m}$ for SST), or the position of the instruments that are located at the bow of the $\mathrm{R} / \mathrm{V}$, that is, far from the center of gravity of the R/V. As a result, the measurement height varies and the vertical wind component is disturbed. Associated with measurements on R/Vs is the issue of the displacement height, which may be difficult to assess (e.g., Brut et al. 2005; Popinet et al. 2004).

Buoys appear to be a good compromise for producing quality air-sea data, although an obvious limitation of buoys is that a ship is required for deployment, recovery, and maintenance, which is again a major operation. In addition, for buoys that are held in place for a long time (more than one month), instruments are more vulnerable to water, salt (corrosion or deposit on sensors), and fouling. To date, the Rosenstiel School of Marine and Atmospheric Science (RSMAS) Air-Sea Interaction Spar (ASIS) buoy is possibly the best attempt at buoy development dedicated to the study of air-sea interactions (Graber et al. 2000). It was recently proven to be successful even in severe weather conditions (Sahlée et al. 2012). Note that in very strong winds, buoys can tilt relative to the vertical (Howden et al. 2008). Measuring fluxes must be very difficult in such conditions with any platform. The ASIS buoy presumably has small aerodynamic distortion and can be equipped with various instruments, which include not only turbulence but also radiation, gas fluxes, and underwater instruments, thanks to its large payload capacity. Although there are few limitations associated with this design, it can be argued that it is rather heavy and large, which may limit the number of deployments. In addition, by its design, ASIS turbulence measurements are made at $3.5-4.5 \mathrm{~m}$ above the surface, whereas the study of turbulence even closer to the surface may be of interest (Grare et al. 2013). Instruments are not at a constant height above the surface. The pertinence of this argument may be discussed. However, for the study of wave-wave wind variation, constant height wind data may be of interest.

To overcome the above-described limitations in designing a new platform, the five following desirable criteria were taken into consideration:

1) Height above the sea surface should be constant, for analyzing wind-wave interaction.

2) Flow distortion, thermal effects, and effect of the platform on waves would have to be small.

3) Wind, temperature, and humidity measurements would be taken at heights smaller than existing designs $(<3 \mathrm{~m})$, and possibly at several heights, for investigating surface boundary layer profiles. 


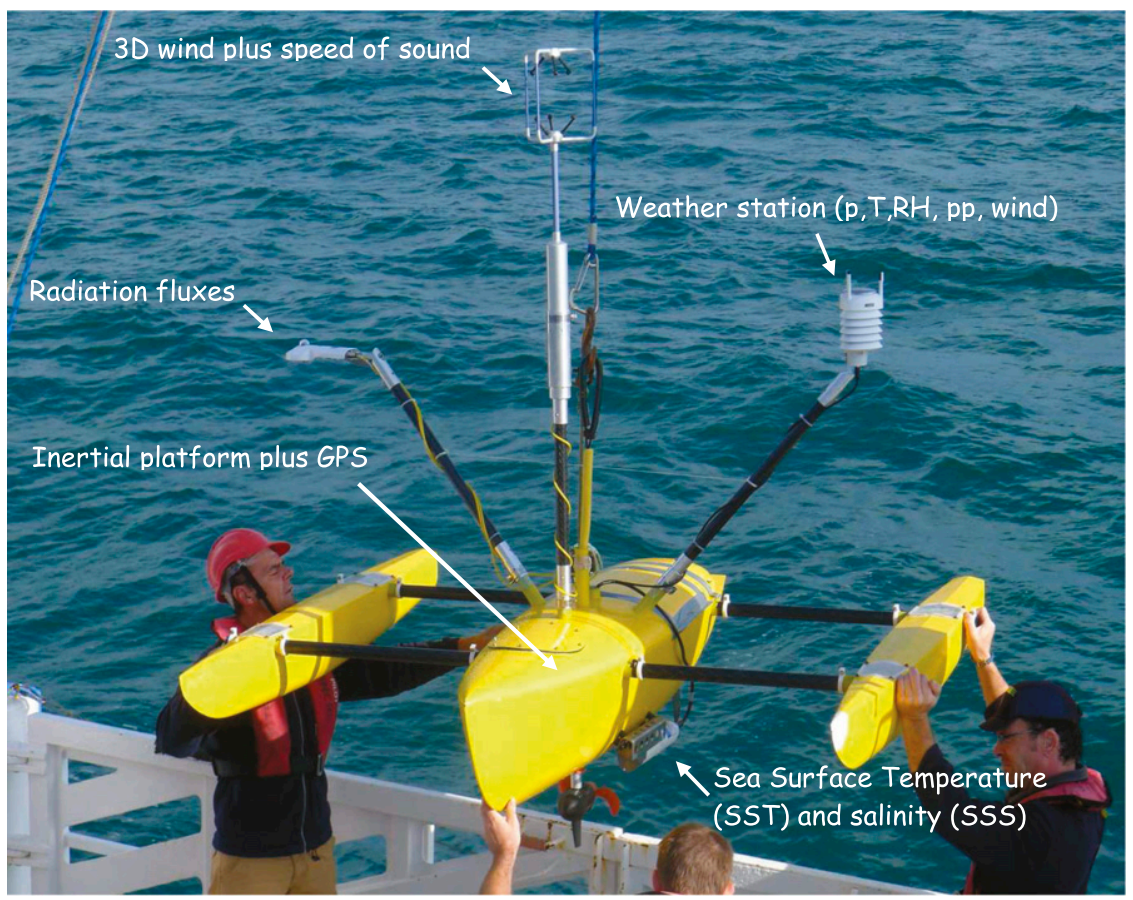

FIG. 1. Deployment of OCARINA from the rear deck of $C D L M$ during the FROMVAR 2011 experiment (Picture by H. Barrois, DT of INSU).

4) Data would be sampled far from the host ship, to avoid the effects of host ship wake and radiation.

5) Deployment and recovery would be as easy as possible, in order to ensure instrument check, cleaning, maintenance, and for maximizing data return.

We propose a new platform design following these criteria: the Ocean Coupled to Atmosphere, Research at the Interface with a Novel Autonomous platform (OCARINA). It is described in section 2. In section 3, we briefly describe the environmental conditions of the experiment during which OCARINA was recently tested. Next in section 4, its main features, including flow distortion and motion characteristics, are discussed. In section 5, different estimates of air-sea fluxes done by this platform are compared and the wind stress angle is analyzed with respect to the mean wind direction. In section 6, eight cases of windwave interaction for which swell and wind travel in the same direction and in the opposite direction are presented, to further check the quality of the wind measurements in the presence of swell. Last, the results are summarized and discussed in section 7 .

\section{Description of the platform}

\section{a. The platform}

The OCARINA platform is a 2-m-long trimaran boat that weighs $\sim 35 \mathrm{~kg}$ (Figs. 1, 2). It has a streamlined shape and a low profile. As such, OCARINA has small aerodynamic distortion whatever the direction of the incoming wind is (see section 4a). OCARINA is motorized with a propeller coupled to an autopilot and a remote control. It can be controlled to follow a particular route, drift as a wave rider, or maintain its position, within the limit of its battery life, which is currently

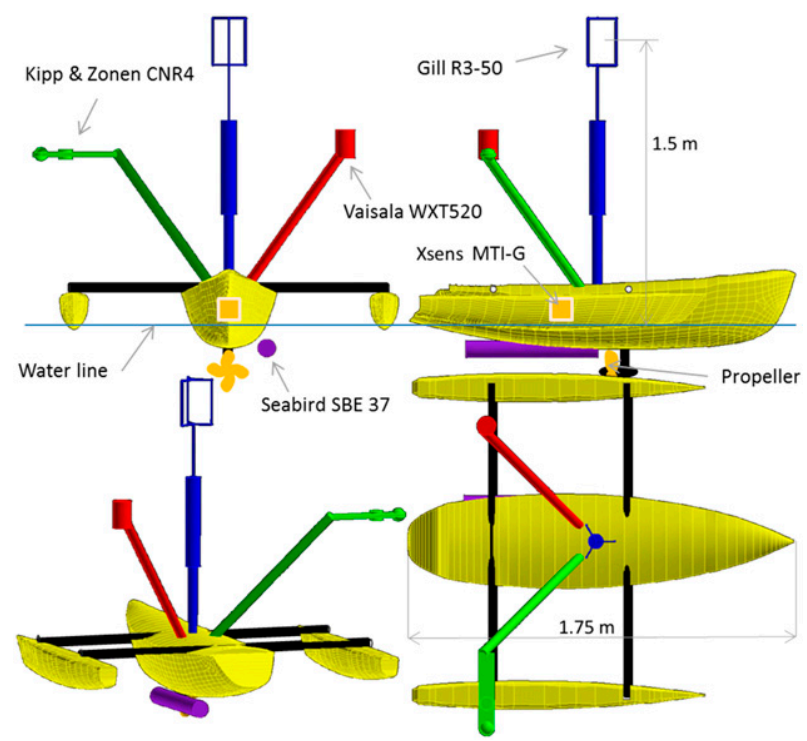

FIG. 2. Conceptual view of the OCARINA platform. 
$3 \mathrm{~h}$ at low speed $\left(1.5 \mathrm{kt} ; 1 \mathrm{kt}=0.51 \mathrm{~m} \mathrm{~s}^{-1}\right)$. Two independent 5000-mAh lithium polymer batteries of five 4.2-V cells each provide power for navigation, communication, science instruments, and data storage, for up to $12 \mathrm{~h}$.

The trimaran configuration was chosen because it reduces self-roll as opposed to monohull designs. Another advantage of the configuration is that the whole payload can be installed on the central float. A catamaran is easier to construct, but the payload has to be split between the two hulls, or it has to be installed in a bulky compartment between the two side hulls.

Weight was kept as low as possible to facilitate transport and deployment. But above all, weight is a key point that conditions structure motion together with the position of the instrument that measures turbulent wind and temperature fluctuations, presently located at the top of a central mast (so-called turbulent mast) on OCARINA, as can be seen in Figs. 1, 2. On OCARINA, the low weight coupled with a turbulent mast at the center of the ship induces minimal vertical motion relative to the surface (the platform does not dive or bounce on the surface). Note, however, that OCARINA presents the characteristic motion of trimarans, which consists of a small precession-like motion, that is, it rotates in circles between its two lateral hulls.

One particular feature that results from its low weight and its large projected horizontal surface is that the trimaran naturally follows the waves. Thus, to some extent (wavelengths larger than $4 \mathrm{~m}$ ), it is possible to deduce wave features just from the recorded motion/ inertial package.

The small size of OCARINA was well appreciated while carrying it on almost every type of host boat. It was even held on the rear deck of a 7-m-long inflatable boat. Thus, it was easily accepted on science experiments, which helps for missions planned at short notice, for example.

Overheating of electronic and mechanical components inside the main float was avoided by choosing an electric engine located in an underwater bulb.

\section{b. Science payload}

The science instruments are installed at five different locations on OCARINA, as illustrated in Figs. 1, 2. There are three masts for atmosphere and radiation measurements, one Sea-Bird Electronics SBE-37 on the side of the main hull for SST and SSS measurements, and one inertial platform at the horizontal center of OCARINA and at the level of the waterline. The inertial platform is an Xsens MTI-G device, which features three magnetometers, three accelerometers, three gyroscopes, a GPS, and a barometer. The MTI-G is light, weighs $70 \mathrm{~g}$, and is small. Motion data are recorded at $50 \mathrm{~Hz}$. The turbulent mast holds a Gill Instruments Limited R3-50 sonic anemometer, at $1.5 \mathrm{~m}$ above the surface. It samples the three wind components as well as sound speed (which is related to the virtual temperature of the air), at the rate of $50 \mathrm{~Hz}$. The port mast holds a Vaisala WXT-520 meteorological station that measures air temperature and humidity, static pressure, rain, and wind, at $1 \mathrm{~Hz}$. The station is located $1 \mathrm{~m}$ above the surface. This characteristic will be further discussed in section 7 . The starboard mast holds a Kipp \& Zonen CNR 4 radiation instrument, which measures upward and downward radiation fluxes in the visible and infrared spectra. Overall, OCARINA samples and records over 50 variables simultaneously. The instruments and sampled variables are summarized in Table 1.

\section{c. Data acquisition, automatic pilot, and transmission}

A specific field-programmable gate array (FPGA)based electronic board was designed for data acquisition. It provides a lightweight, low power consumption, and, above all, reliable method for sampling, sorting, and adding time and date independently for all data. After experiencing data synchronization problems from various serial ports in past experiments, we decided to proceed with on board asynchronous data processing. Every datum has its own time tag. Next, data are put in a heap memory and then stored and duplicated into two memory cards [secure digital (SD) cards] for robustness of the system, as represented in Fig. 3. Time is inferred from an internal clock that is periodically synchronized to a GPS clock signal. This system was tested and verified: the time deviation was never larger than $0.01 \mathrm{~ms}$, which is small compared to the sampling period of the instruments, that is, $20 \mathrm{~m} \mathrm{~s}$.

OCARINA currently has four operational modes. The first mode is a manual mode, which means that OCARINA is remotely controlled by an operator. This mode is helpful for deploying and recovering OCARINA from the host ship in minutes. The second mode is called "waypoint navigation": OCARINA follows a list of programmed waypoints and cruises from one waypoint to the next. This mode can be used for surveys, or to test the impact of wind or wave orientation with respect to the platform. The third mode is "drift then return." OCARINA first records its original position. Next, it drifts for $30 \mathrm{~min}$ and cruises back to its original position, repeatedly. The fourth and last mode is called "record position and route to follow." The boat cruises for $30 \mathrm{~min}$ following the recorded route, and cruises back to its original position. Note that 
TABLE 1. Summary of the instruments installed on OCARINA, and a list of the instrument locations and sampled data. Only the main recorded variables are reported. Various ancillary data are also recorded for control and verification, such as temperature control or accuracy of GPS position data.

\begin{tabular}{|c|c|c|c|c|c|}
\hline Manufacturer & Instrument & Data & Unit & Sample rate $(\mathrm{Hz})$ & Location \\
\hline \multirow[t]{5}{*}{ Vaisala } & \multirow[t]{5}{*}{ WXT520 } & Wind speed & $\mathrm{m} \mathrm{s}^{-1}$ & \multirow[t]{5}{*}{1} & \multirow[t]{5}{*}{ Port mast } \\
\hline & & Air temperature & $\mathrm{K}$ & & \\
\hline & & Air pressure & $\mathrm{hPa}$ & & \\
\hline & & Relative humidity & $\%$ & & \\
\hline & & Precipitation & $\mathrm{mm}$ & & \\
\hline \multirow[t]{4}{*}{ Kipp \& Zonnen } & \multirow[t]{4}{*}{ CNR 4} & Downward solar flux & $\mathrm{W} \mathrm{m}^{-2}$ & \multirow[t]{4}{*}{1} & \multirow[t]{4}{*}{ Starboard mast } \\
\hline & & Downward infrared flux & $\mathrm{W} \mathrm{m}^{-2}$ & & \\
\hline & & Upward solar flux & $\mathrm{W} \mathrm{m}^{-2}$ & & \\
\hline & & Upward infrared flux & $\mathrm{W} \mathrm{m}^{-2}$ & & \\
\hline \multirow[t]{2}{*}{ Gill Instruments } & \multirow[t]{2}{*}{$\mathrm{R} 3-50$} & 3D wind vector $(u, v, w)$ & $\mathrm{ms}^{-1}$ & \multirow[t]{2}{*}{50} & \multirow[t]{2}{*}{ Central mast } \\
\hline & & Virtual temperature & $\mathrm{K}$ & & \\
\hline \multirow[t]{8}{*}{ Xsens } & \multirow[t]{8}{*}{ MTI-G } & Longitude & $\circ$ & \multirow[t]{8}{*}{50} & \multirow[t]{8}{*}{ Central float } \\
\hline & & Latitude & $\circ$ & & \\
\hline & & Altitude & $\mathrm{m}$ & & \\
\hline & & $3 \mathrm{D}$ angular rates & $\operatorname{rad~s}^{-1}$ & & \\
\hline & & 3D angles & $\mathrm{rad}$ & & \\
\hline & & 3D linear speeds & $\mathrm{m} \mathrm{s}^{-1}$ & & \\
\hline & & $3 \mathrm{D}$ accelerations & $\mathrm{ms}^{-2}$ & & \\
\hline & & 3D compass & Arbitrary unit & & \\
\hline Sea-Bird & SBE-37 & SST & $\mathrm{K}$ & 1 & Side of the central float \\
\hline
\end{tabular}

wave data cannot be inferred from recorded motion when OCARINA has its engine on.

OCARINA is controlled via a remote control with a 400-m range, or via satellite (Iridium system). Currently, satellite communication is only used to get the current position of OCARINA and to proceed to its recovery rather than for guidance, given its small operating range, which is $\sim 10 \mathrm{~km}$.

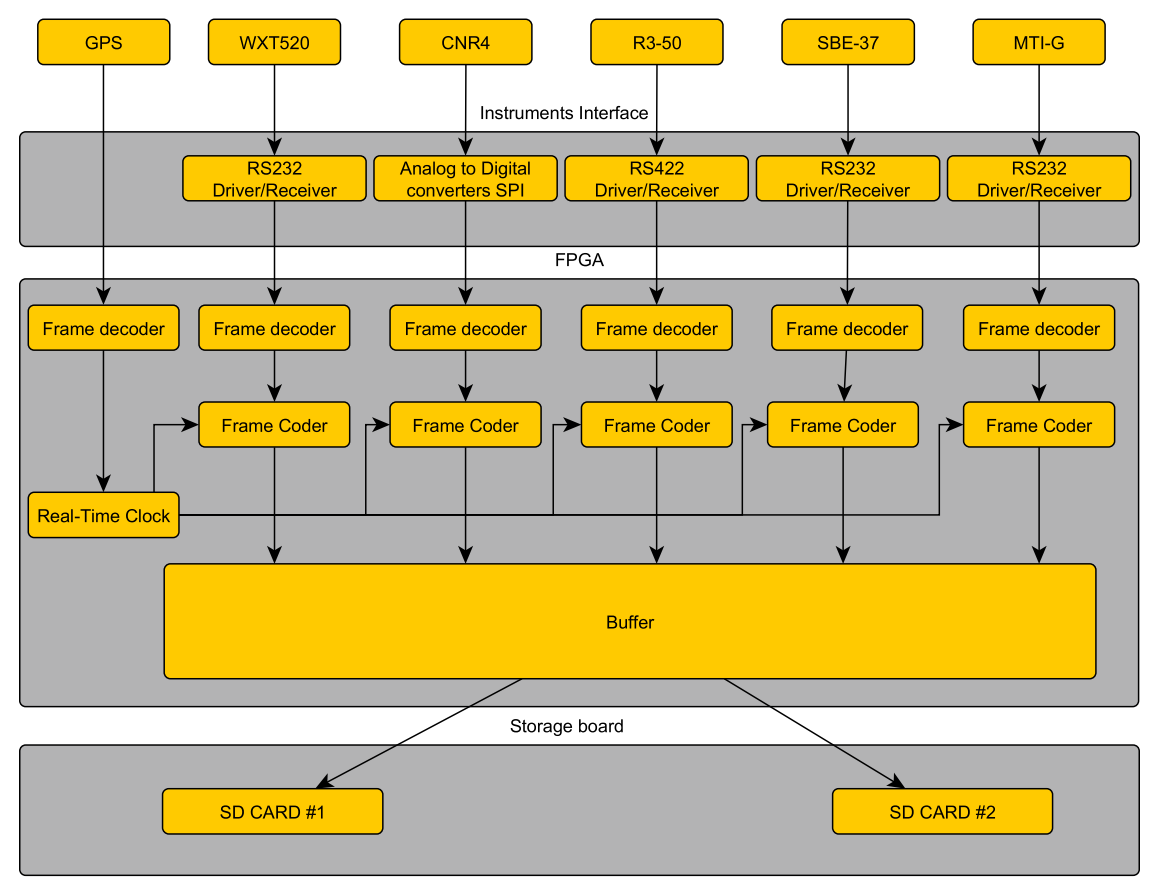

FIG. 3. Flowchart of the data acquisition system. The data frames of each instrument (top row) are decoded. Next, a time tag based on a GPS clock is added, before the frames are stored in a buffer (middle row). When the buffer is full, its content is transferred to two SD cards, in parallel (bottom row). 


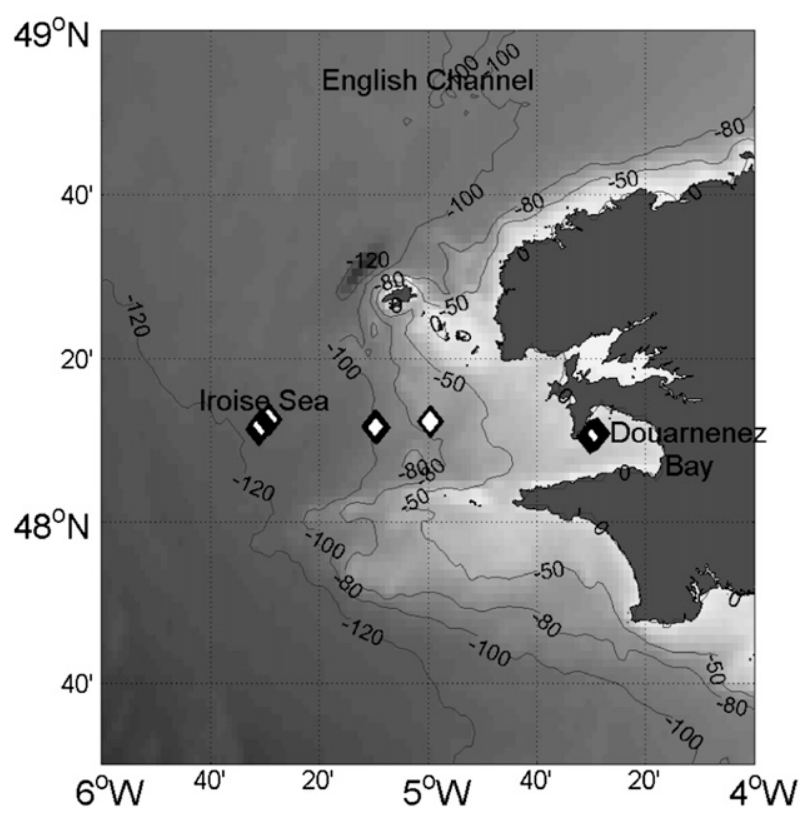

FIG. 4. Locations from which OCARINA was operated during the FROMVAR 2011 experiment. The bathymetry is indicated with contour lines.

\section{The FROMVAR 2011 experiment}

The Front de Marée, Variabilité (FROMVAR), project was devoted to the study of the Ushant tidal front in Mer d'Iroîse, off the west coast of Brittany, France, which results from the tidal actions and air-sea interactions (http:// wwz.ifremer.fr/epigram/Acces-aux-donnees/Campagnes/ FROMVAR; Le Boyer et al. 2009). FROMVAR aimed at understanding the hydrological structure, the currents, and the dynamical processes associated with this front. The project consisted of several 1-2-week experiments every year since 2007. OCARINA was part of the last experiment, from 10 to 15 September 2011. In addition to OCARINA, air-sea flux data were acquired during every experiment, on board the French Institut National des Sciences des l'Univers (INSU) R/V Côtes de la Manche $(C D L M)$, which is $26 \mathrm{~m}$ long. Unfortunately, not enough data were sampled in order to get a reliable comparison between the two platforms. Therefore, the CDLM flux estimates will not be discussed in the present paper.

During FROMVAR, OCARINA was deployed eight times in five days, from $30 \mathrm{~min}$ to more than $2 \mathrm{~h}$ each time. The locations at which OCARINA was deployed during the cruise of the $C D L M$ are represented in Fig. 4. Bathymetry ranged from $\sim 20$ to $\sim 120 \mathrm{~m}$. Several deployments were conducted in the Bay of Douarnenez, thus not in open sea conditions. The 14 different weather conditions (referred to as 14 cases in the following) encountered during the experiment were from low to moderate wind speeds, from $\sim 1$ to $\sim 8 \mathrm{~m} \mathrm{~s}^{-1}$, as reported in Table 2 (column 6). The surface boundary layer was either unstable or stable, with sometimes strong thermal stratification (Table 2). In the most stable case, the maximum difference between air temperature and sea surface temperature was equal to $+1.1^{\circ} \mathrm{C}$, with the formation of gravity waves in the boundary layer, as independently inferred from lidar measurements. Significant wave heights $H$ were estimated with OCARINA data; $H$ was calculated as 4 times the standard deviation of the elevation $(\eta$, which is the difference between the actual vertical position and the mean sea level), an output from the MTI-G instrument. The $H$ estimates ranged from 1.1 to $3.3 \mathrm{~m}$. OCARINA significant wave height estimates were already compared to two buoy datasets in the report by Morisset and Reverdin (2011). Their conclusion is that

TABLE 2. Stability, wind, and wave conditions during the FROMVAR 2011 experiment, where $U_{r}$ is the relative wind speed with respect to OCARINA and TA is air temperature measured at $1 \mathrm{~m}$. The wind-wave angle is the difference between the angle of the true wind (wind with respect to ground) vector and the direction where the waves go. Both angles are counted counterclockwise.

\begin{tabular}{|c|c|c|c|c|c|c|c|c|}
\hline Case No. & Date & Time & $H(\mathrm{~m})$ & $\mathrm{SST}-\mathrm{TA}(\mathrm{K})$ & SSS (psu) & $\left|U_{r}\right|\left(\mathrm{m} \mathrm{s}^{-1}\right)$ & $\begin{array}{l}\text { Wind-wave } \\
\text { conditions }\end{array}$ & Wind-wave angle $\left({ }^{\circ}\right)$ \\
\hline 1 & 12 Sep 2011 & 0818:11 & 1.3 & -1 & 35.383 & 8.7 & & -10 \\
\hline 2 & & 0836:31 & 1.2 & -1 & 35.375 & 8.3 & & -11 \\
\hline 3 & & 0854:51 & 1.2 & -1 & 35.357 & 8 & & -19 \\
\hline 4 & & 0913:11 & 1.3 & -0.8 & 35.344 & 7 & & -21 \\
\hline 5 & & 0931:31 & 1.1 & -0.7 & 35.380 & 7.2 & & -23 \\
\hline 6 & & 0949:51 & 1.1 & -0.7 & 35.393 & 6.7 & & -26 \\
\hline 7 & 14 Sep 2011 & 0722:51 & 3.3 & -0.5 & 35.538 & 2.6 & Following swell & 17 \\
\hline 8 & & 0741:11 & 3.0 & -0.4 & 35.537 & 2.7 & & 17 \\
\hline 9 & & 0759:31 & 3.2 & -0.5 & 35.537 & 2.3 & & 30 \\
\hline 10 & & 1709:31 & 2.6 & 0.8 & 35.329 & 2 & & -50 \\
\hline 11 & 15 Sep 2011 & 0813:57 & 1.9 & 1.2 & 35.320 & 6.4 & Counter swell & -173 \\
\hline 12 & & 0832:17 & 2.1 & 1.2 & 35.277 & 6.4 & & -173 \\
\hline 13 & & 0927:17 & 1.9 & 1.2 & 35.174 & 6.1 & & -183 \\
\hline 14 & & $1325: 37$ & 1.6 & -1.1 & 35.534 & 1.4 & & -240 \\
\hline
\end{tabular}


a)

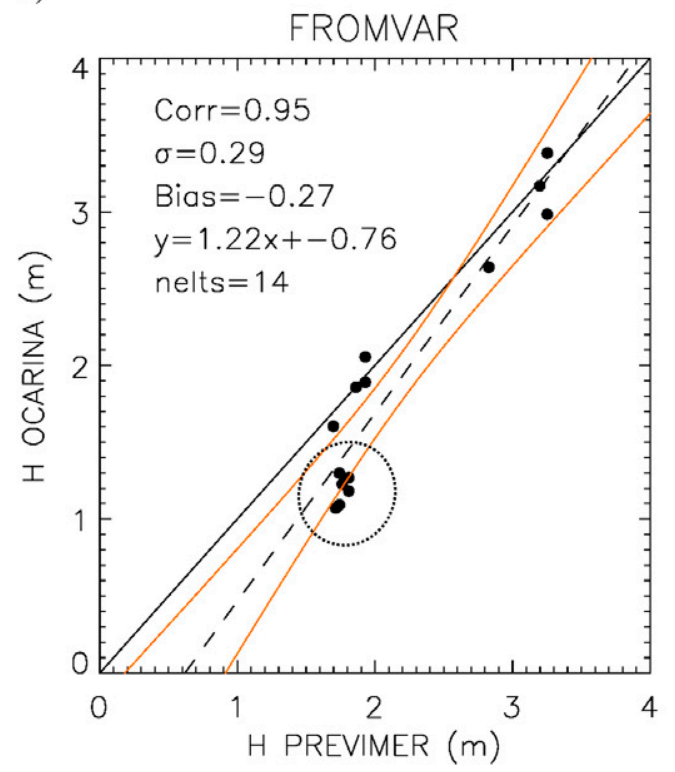

b)

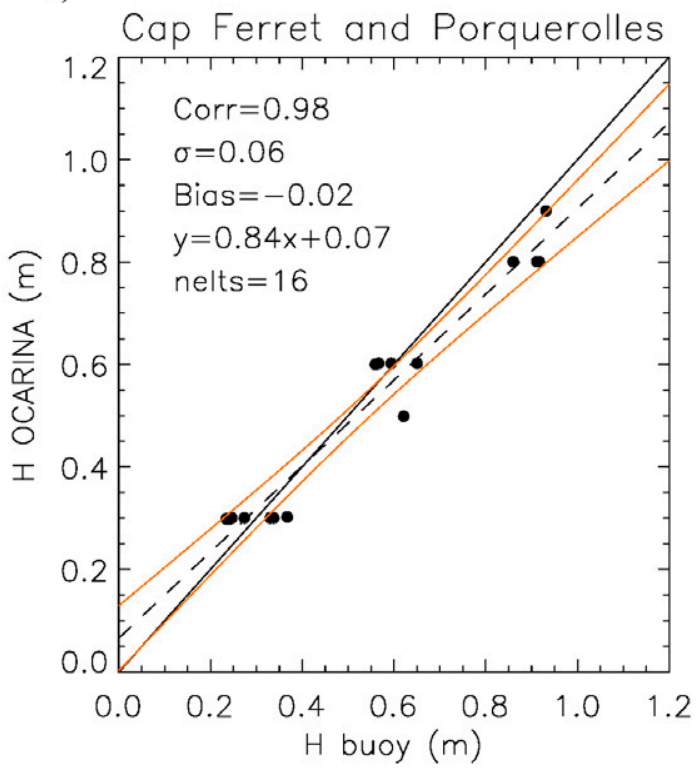

FIG. 5. (a) Comparison between $H$ from PREVIMER model and OCARINA estimates. The dashed lines indicate the linear fits between $H$ estimates on the $x$ and $y$ axes. The red lines indicate the $95 \%$ confidence interval for the linear fit. The dots in the black circle correspond to data taken in shallow water. (b) The estimates of $H$ were compared to reference wave buoy data, near Porquerolles and Cap Ferret, which were collected during the first tests of OCARINA, in 2010. "Nelts" means number of elements/cases in this and later figures.

OCARINA underestimates the wave height for wavelengths smaller than $4 \mathrm{~m}$, which was expected because it is on the order of the size of OCARINA. It is likely then that the physical configuration of OCARINA and its dynamical interaction with the surface act as a low-pass filter with respect to the recorded motion of small spatial wavelengths. A further comparison of OCARINA-derived wave heights to output fields from the PREVIMER preoperational prediction system for coastal environment (Lecornu and De Roeck 2009; see also http://www. previmer.org/en) is presented in Fig. 5a. Although it is not a strict validation of OCARINA data, PREVIMER was chosen because it was the only available source for estimating wave characteristics in the investigated area. The root-mean-square (rms) deviation between PREVIMER and OCARINA estimates of $H$ is $0.3 \mathrm{~m}$, which is acceptable, although small wave heights do not compare well. Note that the outliers in Fig. 5a correspond to small and short waves in shallow water, which could be misrepresented both in the model and in OCARINA data. To assess the accuracy of $H$ estimates for small but long waves, an additional comparison based on data collected in 2010 in the vicinity of Porquerolles (near Marseille, France) and Cap Ferret (near the Landes coast, France) is presented in Fig. 5b. The values of $H$ deduced from OCARINA data are compared to reference buoy data (buoy Porquerolles 61004 and buoy Cap Ferret 62064).
The rms deviation between OCARINA and buoy estimates is $0.06 \mathrm{~m}$, which is encouraging.

\section{Distortion and motion characteristics}

\section{a. Flow distortion}

Simulations were performed following the method described in Bourras et al. (2009). The fluid simulation software used is an industry standard named "Fluent," from ANSYS, Inc. The air volume that encompasses the OCARINA surface is $20 \mathrm{~m}$ long $\times 20 \mathrm{~m}$ wide $\times 10 \mathrm{~m}$ tall. This air volume is gridded with an unstructured mesh, based on tetrahedral elements, the size of which is smaller, close to OCARINA. Several flow solvers, including laminar and the Reynolds stress model, were tested. They gave qualitatively similar results. The results presented in Fig. 6 are based on laminar simulations. Even in the worst-case scenario, when the wind comes across OCARINA, vertical wind distortion should be $\sim 3^{\circ}$ at $1.5 \mathrm{~m}$ above the platform, as shown in Fig. 6, which is less than half what is found for a $50-80-\mathrm{m}-$ long $\mathrm{R} / \mathrm{V}$, that is, $7^{\circ}-10^{\circ}$ (Bourras et al. 2009). In addition, distortion is smaller than $3^{\circ}$ if the wind comes from other directions, which is an advantage over large R/Vs for which $6^{\circ}$ is a minimum value that increases with the wind angle (Bourras et al. 2009). At the location of the portside 


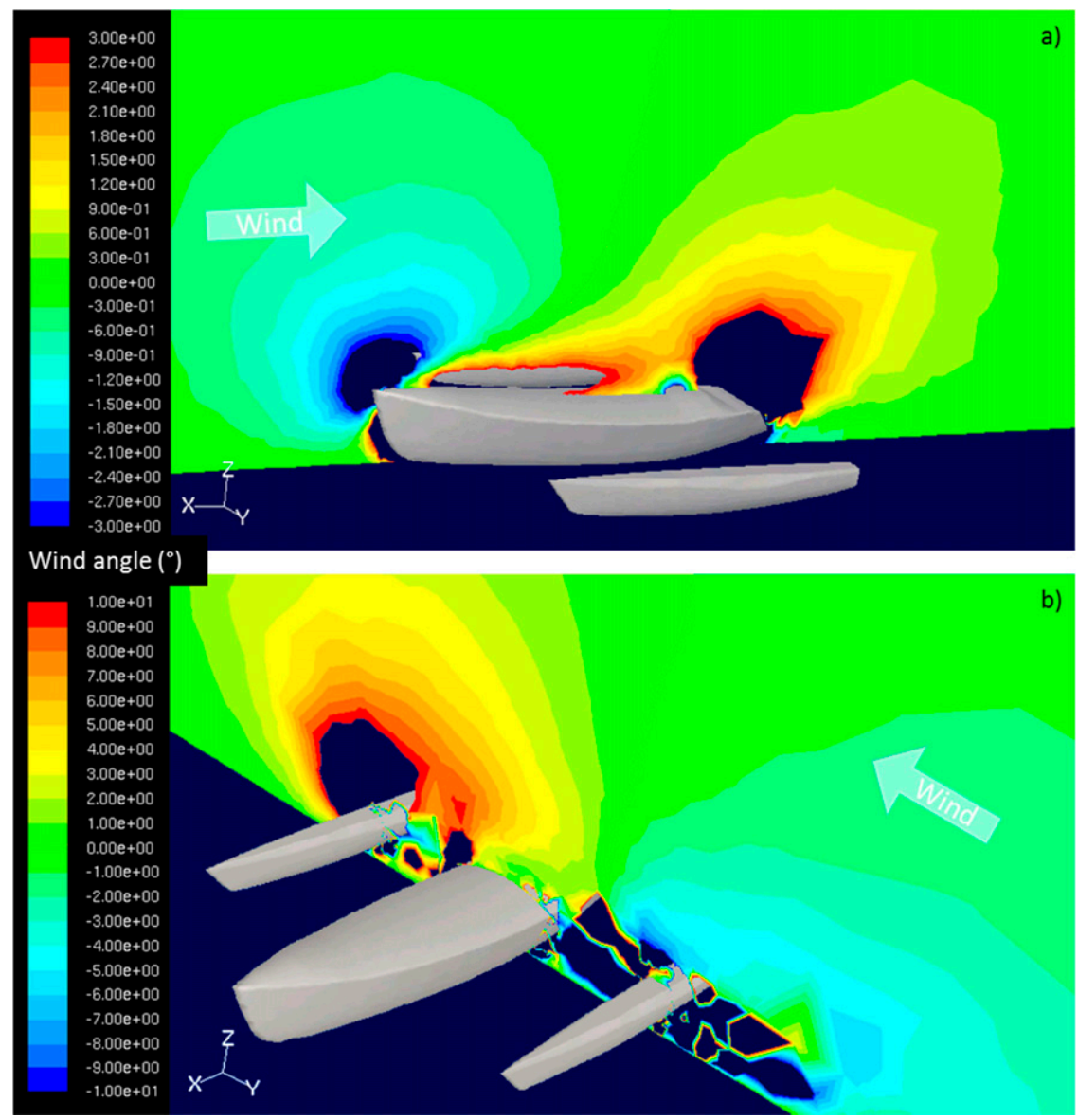

FIG. 6. (a),(b) Numerical simulations of the vertical wind angle $\left(^{\circ}\right)$, with the hypothesis that OCARINA is horizontal. In (a), wind is aligned with the longitudinal axis of the boat, whereas the wind comes from the portside of the boat in (b). Gaps in (a),(b) correspond to regions where the absolute value of the angle is larger than $3^{\circ}$ and $10^{\circ}$, respectively.

meteorological mast (at 1-m height), the simulations indicate that distortion is on the same order of magnitude as for the vertical mast at $1.5 \mathrm{~m}$. Note that in the simulations, OCARINA is assumed to be horizontal, which is the case for averages over time periods larger than some minutes. For shorter time periods, steady simulations would not be meaningful without taking into account both waves and OCARINA motion, which was not attempted.

According to FROMVAR observations, the mean vertical wind angle is $1.27^{\circ}$ at the height of $1.5 \mathrm{~m}$, as can be calculated from the angle values reported in Table 3 for the 14 cases. Thus, the actual distortion angles are $\sim 2^{\circ}$ smaller than in the simulations presented above, which is encouraging. Similarly, the mean vertical velocity is $0.12 \mathrm{~m} \mathrm{~s}^{-1}$, which is small compared to the velocity commonly found for research vessels, that is, $\sim 1 \mathrm{~m} \mathrm{~s}^{-1}$ (e.g., Bourras et al. 2009). It was determined that rotation of the wind vector of an angle that would cancel the mean value of the vertical wind component had a very limited impact on the estimates of turbulent fluxes. It was concluded that it was not necessary to apply any distortion correction to the OCARINA data.

\section{b. Motion and its impact on wind measurements}

Understanding how OCARINA moves on waves as a function of data sampling frequency is important because its shape and characteristics are different from other platforms. A typical wind and motion power

TABLE 3. Mean vertical distortion angle $\left(^{\circ}\right)$ and vertical wind component $\left(\mathrm{m} \mathrm{s}^{-1}\right)$ for each 20 -min bin.

\begin{tabular}{|c|c|c|c|c|c|c|c|c|c|c|c|c|c|c|}
\hline Case & 1 & 2 & 3 & 4 & 5 & 6 & 7 & 8 & 9 & 10 & 11 & 12 & 13 & 14 \\
\hline Angle & 1.1 & 1.6 & 1.6 & 1.4 & 1.6 & 1.5 & 0.9 & 1.2 & 0.5 & 0.2 & 0.5 & 0.4 & 1.3 & 3.1 \\
\hline$w$ & 0.26 & 0.24 & 0.23 & 0.17 & 0.20 & 0.17 & 0.04 & 0.05 & 0.02 & 0.01 & 0.06 & 0.04 & 0.14 & 0.06 \\
\hline
\end{tabular}




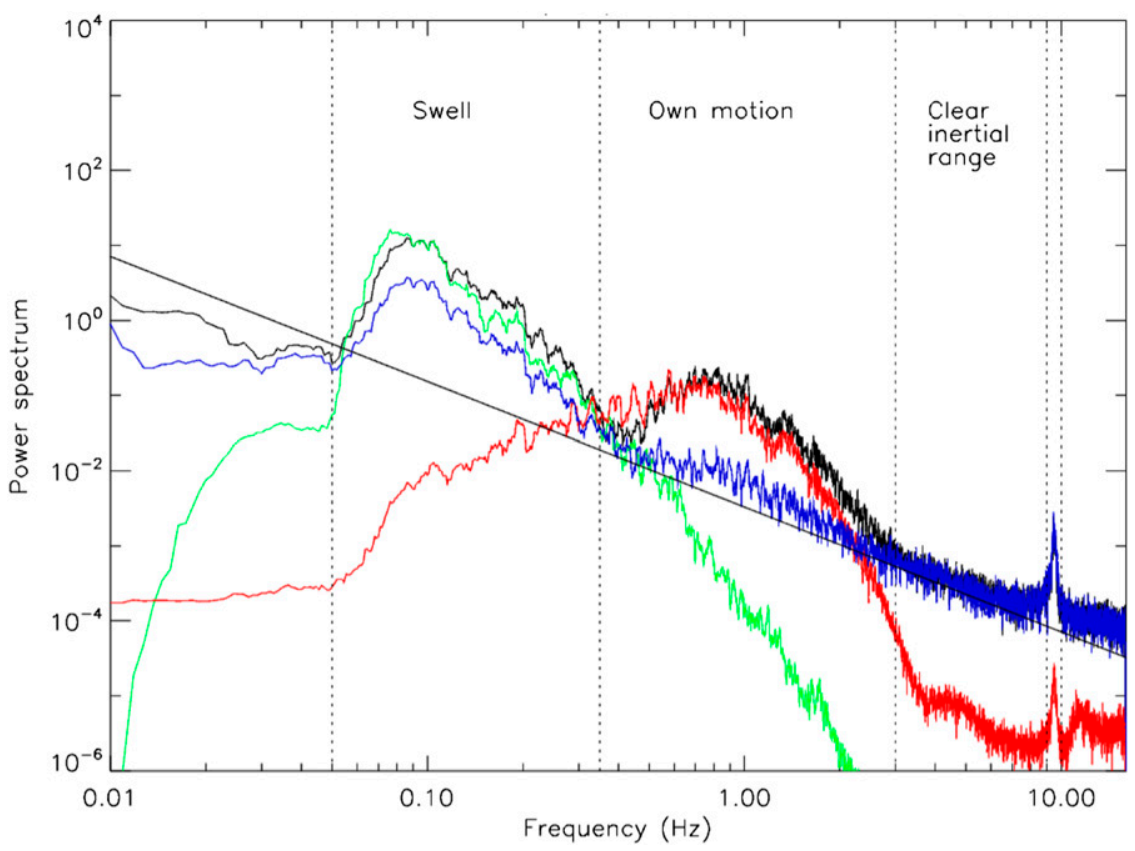

FIG. 7. Noncorrected horizontal wind component (black), sea elevation (green), linear speed due to roll angle (red), and corrected horizontal wind component (blue). The oblique black line shows the $-5 / 3$ slope within the $\log / \log$ axis.

spectrum is presented in Fig. 7, for a 20-min interval that started at 0722 UTC 14 September 2011, when the swell was largest. The relative wind curve (in black) reveals two broad peaks that correspond to swell (centered on $0.1 \mathrm{~Hz}$ ) and to the resonating frequency of OCARINA (at $1 \mathrm{~Hz}$ ). The swell peak corresponds well to the peak in the power spectrum of $\eta$ (green curve). To assess whether the relationship between swell and wind is physical or is due to variations of ship attitude and motion, we performed a true wind calculation, as fully described in Pedreros et al. (2003). After application of the correction, the power spectrum of the along-wind component (blue curve on Fig. 7) still presents a large peak at the frequency of the swell. As a result, the peak in wind is actually related to a physical relationship between wind and swell. This relation will be further analyzed in section 6 .

The peak at $1 \mathrm{~Hz}$ in Fig. 7 fits the linear velocity of OCARINA (deduced from roll angular velocity). After application of the correction, the peak is almost totally removed, which confirms that it was almost totally related to OCARINA motion.

Note the presence of a sharp peak at $10 \mathrm{~Hz}$ in Fig. 7 that presumably corresponds to a flexion mode of the turbulent mast, which is a vertical carbon tube, in interaction with the structure of the platform.

The frequency range that can be used for estimating fluxes with the spectral method, or ID method, in the following (Dupuis et al. 1997) is restricted to 3-9 Hz without correction because in this range, the slope of the linear fit to data is the closest to the value of $-5 / 3$, which is nominal for applying the ID method. Note that after correction, the frequency range could be extended to frequencies in the 1$3-\mathrm{Hz}$ range. However, only the $3-9-\mathrm{Hz}$ band was used because it is sufficient for applying the ID method.

In contrast, for the EC method the maximum frequency of the wind or temperature data was restricted to $2 \mathrm{~Hz}$ with a first-order low-pass filter. This cutoff frequency corresponds to the end of the turbulence production range and to the beginning of the "clean" inertial range, as illustrated in Fig. 7. The filter was applied so as to avoid parasite signals, such as the peak at $10 \mathrm{~Hz}$ in Fig. 7. The impact of this filter was tested: if no filter was applied, then the EC method slightly overestimated the other fluxes. In addition, the application of the filter improved the comparisons to the bulk and ID methods.

\section{Air-sea fluxes}

Friction velocity $u^{*}$ is related to the turbulent momentum flux, which is $\left(\overline{u^{\prime} w^{\prime}} / \overline{v^{\prime} w^{\prime}}\right)$ in vector form, where $u^{\prime}, v^{\prime}$, and $w^{\prime}$ are the turbulent fluctuations of the wind in the along-wind, crosswind, and vertical directions, respectively. The relation between $u^{*}$ and the momentum flux is written as 
a)

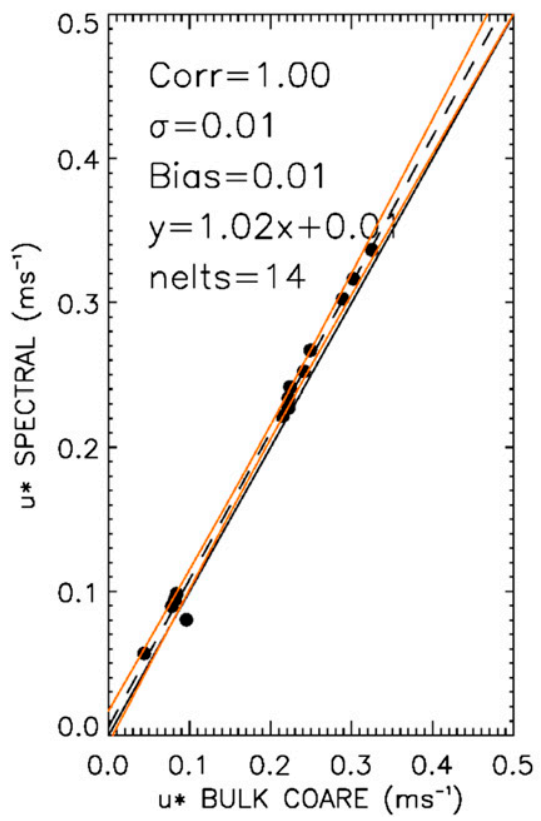

b)

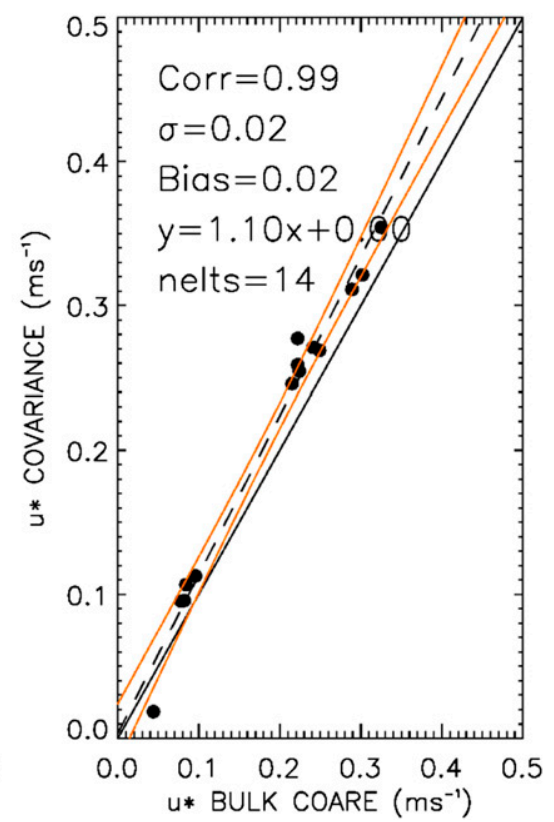

c)

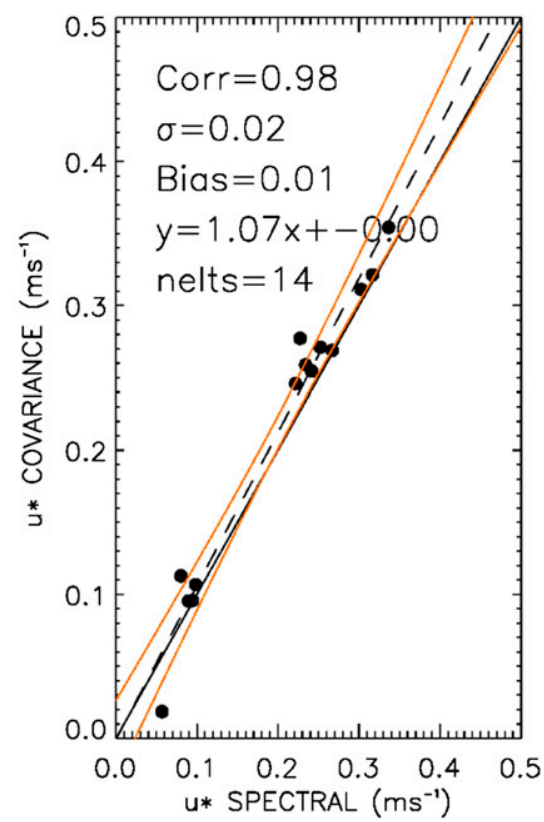

FIG. 8. Comparison between $u^{*}$ values calculated with three different methods: (a) ID (spectral) vs bulk, (b) EC (covariance) vs bulk, and (c) EC vs spectral. The red lines indicate the $95 \%$ confidence interval for the linear fit. The cutoff time period of the high-pass filter was set to $1000 \mathrm{~s}$ for the EC method.

$$
u^{*}=\left({\overline{u^{\prime} w^{\prime}}}^{2}+{\overline{v^{\prime} w^{\prime}}}^{2}\right)^{1 / 4}
$$

In the present paper, $u^{*}$ was estimated with the bulk method, the ID method, and the EC method. The comparisons between the three estimates of $u^{*}$ are encouraging in spite of the small number of points available, as shown in Fig. 8. The rms deviation is $0.02 \mathrm{~m} \mathrm{~s}^{-1}$ between both EC $u^{*}$ and bulk $u^{*}$, and between EC $u^{*}$ and ID $u^{*}$, which is good compared to $\mathrm{R} / \mathrm{V}$ data (e.g., Pedreros et al. 2003). However, the slope of the linear fit between EC $u^{*}$ values and bulk or ID $u^{*}$ estimates is 1.1-1.07, which implies that large EC $u^{*}$ values are higher compared to the bulk and ID values of $u^{*}$.

To analyze why there is an overestimation for EC $u^{*}$ values, the cospectra of $-u^{\prime} w^{\prime}$ were calculated as a function of a normalized frequency $(f z / U)$ and the experimental values found were compared to the empirical universal model of Kaimal et al. (1972), as shown in Fig. 9. Cases with a similar behavior were grouped together, namely, moderate wind (Figs. 9a,b; Table 2, rows 1-6 and 11-13), light wind and unstable conditions (Fig. 9c; Table 2, line 10), light wind and stable conditions (Fig. 9d; Table 2, rows 7-9), and no wind and stable conditions (Fig. 9e; Table 2, row 14). In Figs. 9a,b, there is an overall good agreement between the model of Kaimal et al. (1972) and OCARINA data. However, at time periods larger than $20 \mathrm{~s}$, the data have higher spectrum power than the model. In contrast, in light wind conditions (Figs. 9c,d), the model and data do not agree well. Specifically, in stable cases (Figs. 9d,e) there is a peak in the OCARINA cospectra at $f z / U=0.5-0.9$, which is not present in the model. As a test, the EC time series of $u^{\prime}$ and $w^{\prime}$ were high passed with decreasing cutoff time periods $T$ from 1000 to $20 \mathrm{~s}$. For each test, the rms and systematic deviations between EC and bulk $u^{*}$ estimates were checked. The best agreement was found with $T=35 \mathrm{~s}$, which is shown in Figs. 10b,c. The rms deviation between the different $u^{*}$ estimates is $0.01 \mathrm{~ms}^{-1}$, and the slope of linear fit is $0.96-0.99$, which is rather good. This indicates that for this platform there is a strong sensitivity to the cutoff period retained for estimating the covariance fluxes.

No humidity fluctuations were available with the set of instruments installed on OCARINA during FROMVAR. As a result, the latent heat flux could not be estimated with the EC method or the ID method. As the sensible heat flux also depends on humidity, a virtual sensible heat flux Hsv, better known as the buoyancy flux, was calculated instead.

The comparisons between Hsv estimated with the EC method, with the ID method, and with the bulk method are shown in Figs. 10d-f, respectively. Although there are not enough points of comparison to draw firm conclusions, the comparisons between EC and bulk Hsv 
a)

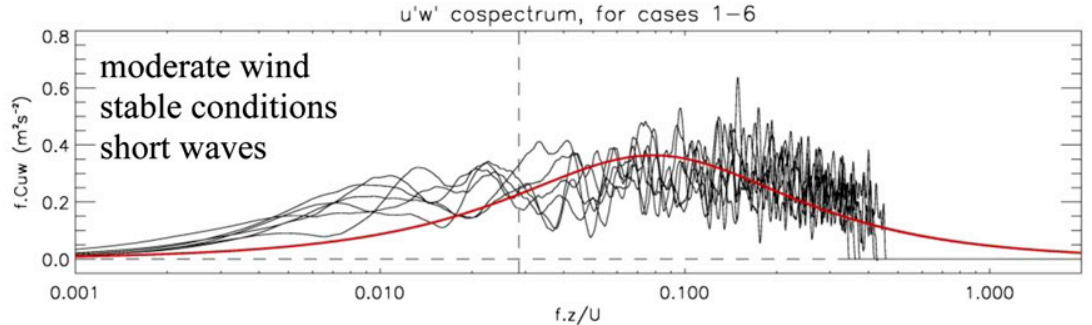

b)

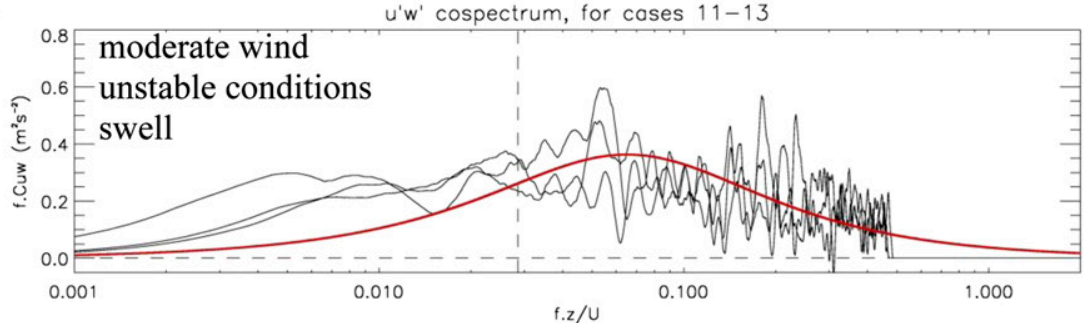

c)

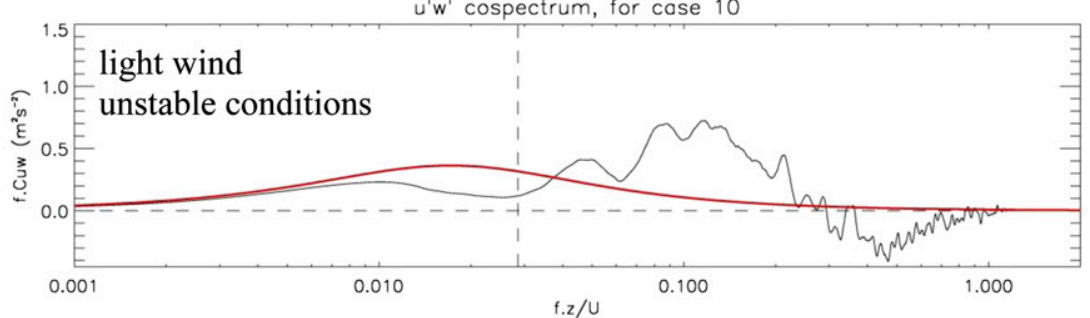

d)

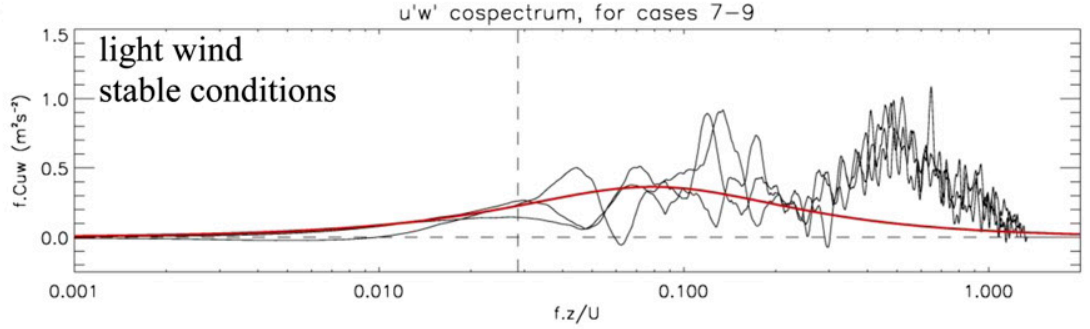

e)

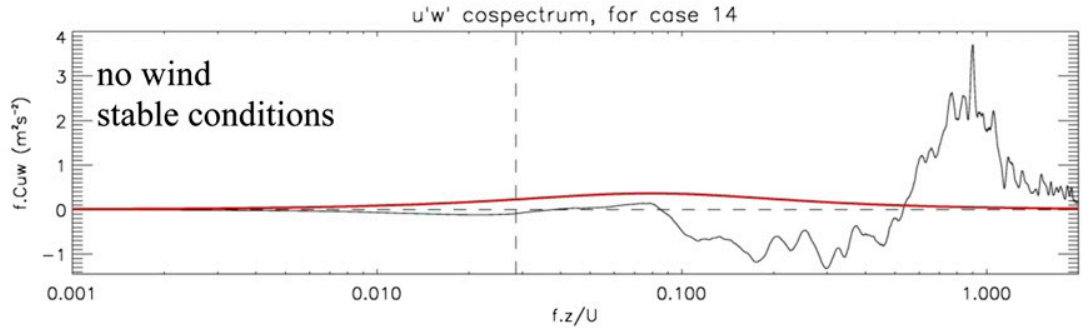

FIG. 9. Cospectra of $u^{\prime} w^{\prime}$ for the 14 cases. Cases that presented a similar behavior were grouped. The red line represents the empirical model of Kaimal et al. (1972).

values are encouraging (Figs. 10d,e). The rms deviation between EC (ID) and bulk Hsv values is 2.5 (3.3) $\mathrm{W} \mathrm{m}^{-2}$, which is reasonable. However, the results presented in Fig. 10e indicate that in stable cases the large negative ID Hsv values are overestimated in comparison to the bulk values. The comparison between EC and ID Hsv values further reveals that the range of ID Hsv values is globally too large with respect to the range of
EC Hsv values, as shown in Fig. 10f. The sensitivity of the bulk estimates to several input parameters inside the Coupled Ocean-Atmosphere Response Experiment (COARE) algorithm (Fairall et al. 2003), namely, jwave, jwarm, and jcool, which relate to the parameterization of the aerodynamic roughness length and to the skin minus bulk sea temperature calculation, was further tested. This had little impact on the results. We 
a)

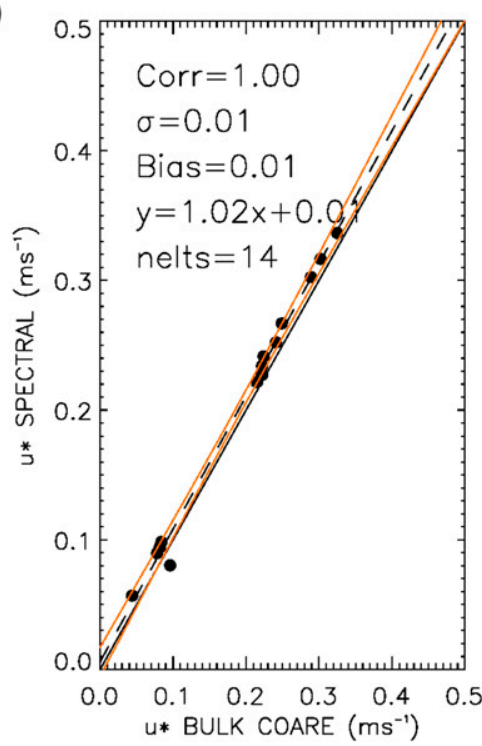

d)

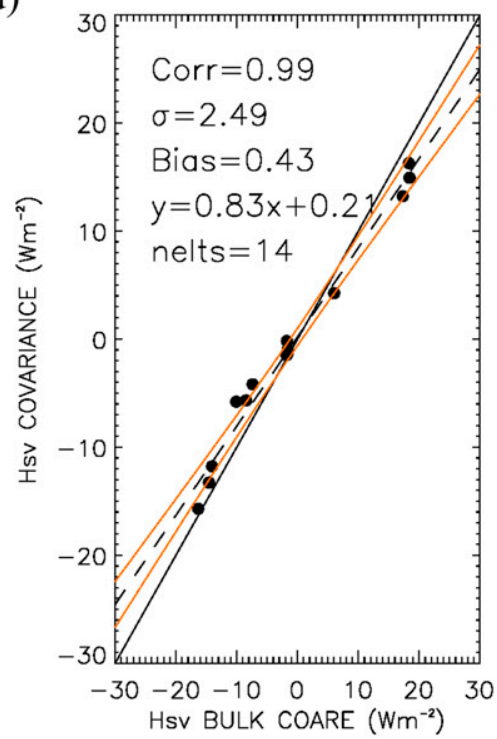

b)

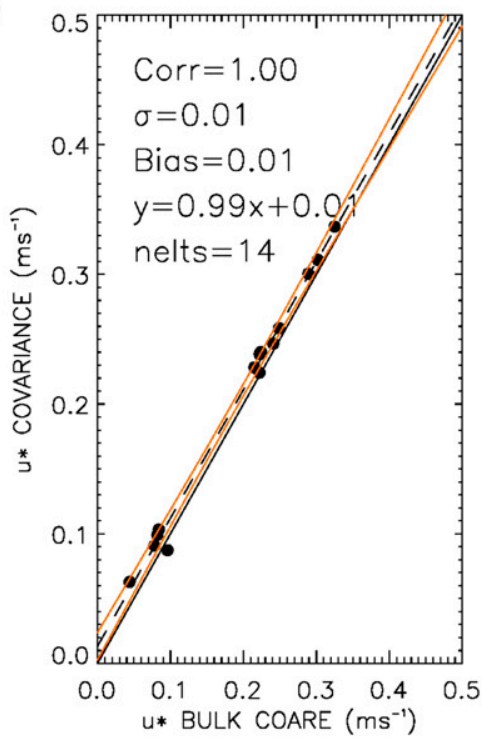

e)

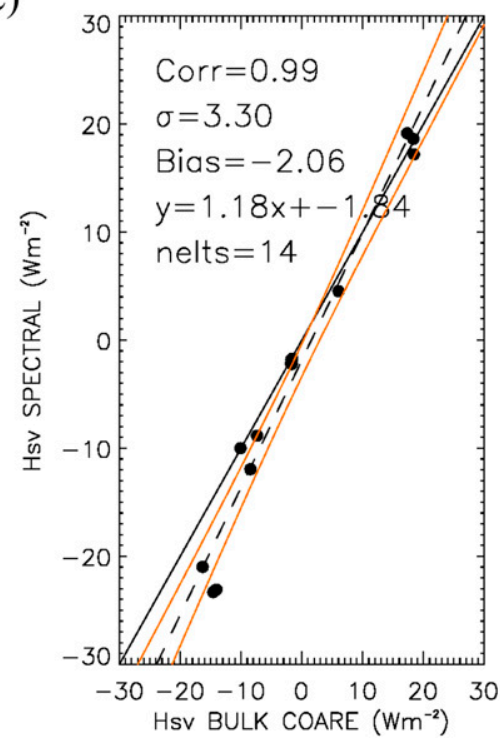

c)

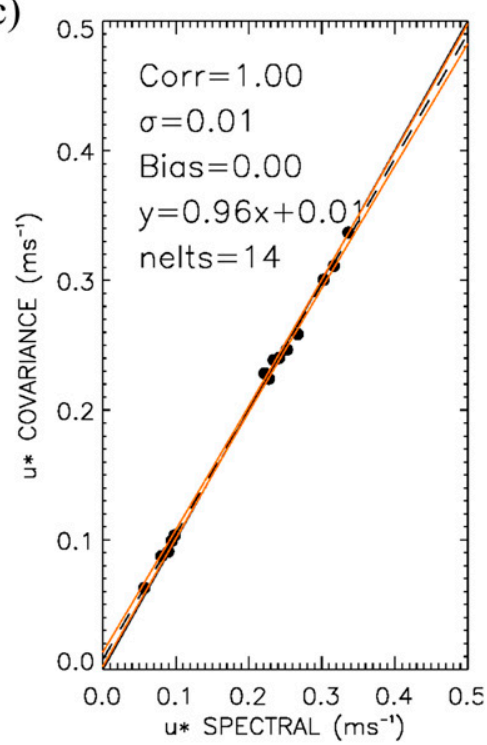

f)

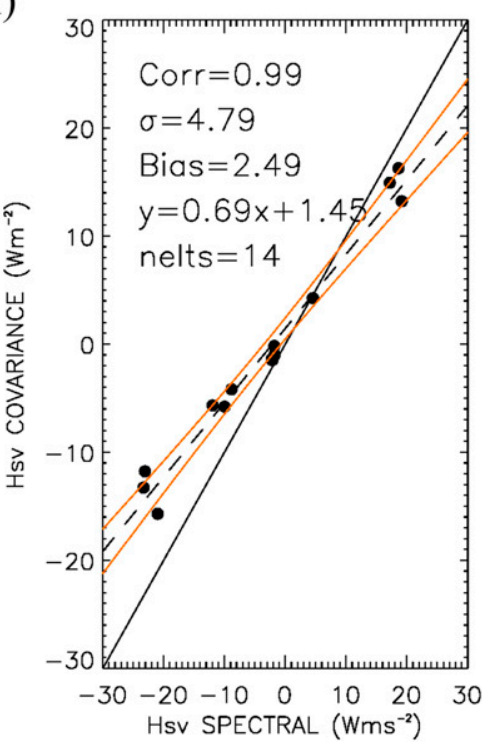

FIG. 10. Comparison between $u^{*}$ (top) and Hsv (bottom) estimates from three different methods (EC, ID, and bulk). The red lines indicate the $95 \%$ confidence interval for the linear fit. The cutoff time period of the high-pass filter was set to $35 \mathrm{~s}$ for application of the EC method.

also attempted to account for the surface current from PREVIMER analyses in the calculation of the bulk estimates but this also had little impact on the results. Thus, for this platform, we recommend for Hsv to use EC or bulk estimates, but not the ID estimates of Hsv.

As two anemometers were available on OCARINA (at 1 and $1.5 \mathrm{~m}$ ), we also attempted to estimate $u^{*}$ values with the profile method, which is written as

$$
u^{*}=\frac{\kappa}{\left[\ln (1.5)-\Psi\left(\frac{1.5}{L}\right)+\Psi\left(\frac{1}{L}\right)\right]}\left(U_{1.5}-U_{1}\right),
$$

where $\kappa$ is the von Kármán constant, equal to $0.4 ; L$ is the Monin-Obukhov length; and the $\Psi$ function chosen follows Smith (1988). Comparisons between estimates of $u^{*}$ calculated according to the profile method and to the bulk method are presented in Fig. 11. As shown in Fig. 11, the profile and bulk methods produce comparable $u^{*}$ estimates when the wind blows from the port side of OCARINA. We hypothesize that if the wind is coming from the starboard side, the starboard mast may disturb the wind at the location of the WXT-520 weather station (which is then in the wake of the starboard mast). The good performance of the profile method is 


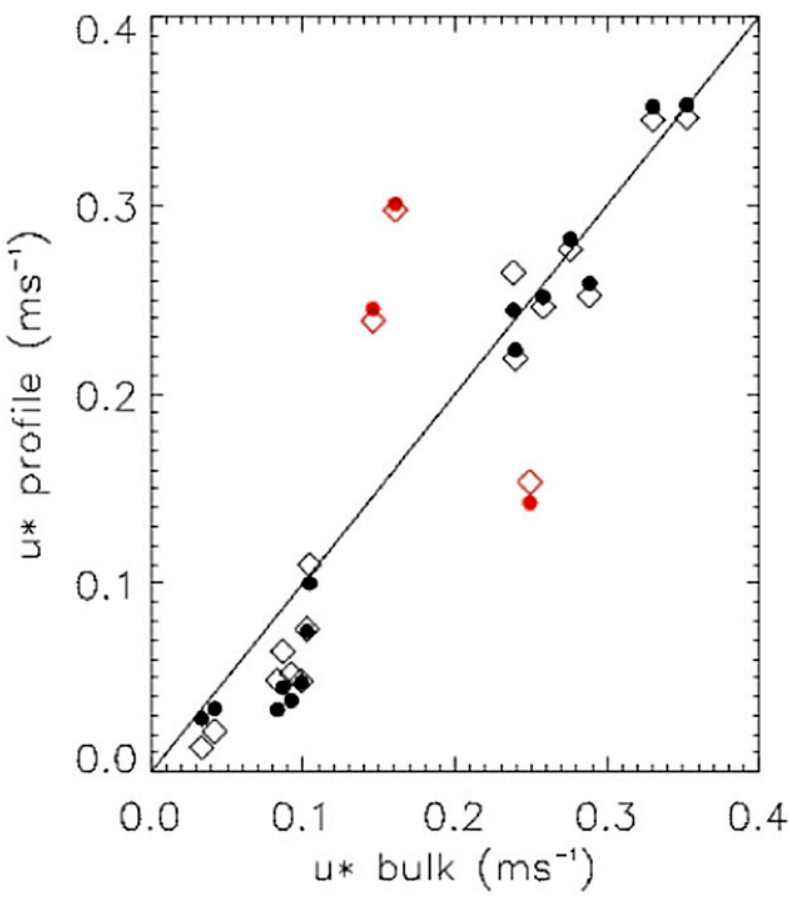

FIG. 11. Comparison of $u^{*}$ values estimated with the profile method and with the bulk method. The red marks correspond to situations when the wind came from the starboard side of OCARINA, for which there may be an aerodynamic masking effect because of the starboard mast and the central mast. The empty diamonds correspond to calculations that account for stability, whereas the dots correspond to a neutral surface boundary layer hypothesis.

uncommon, because it is challenging to apply it at sea for two reasons: either data are sampled at heights that are too large, in which case the wind variations between the two levels are too small to be detected (because the curvature of the log profile is large only at small heights), or because of height-dependent flow distortion, which is difficult or impossible to correct. Note that the results were hardly changed whether stability was accounted for or not in the calculation, as also shown in Fig. 11, which possibly results from the small $w$, thus a small $z / L$. This suggests that in certain conditions, the wind profiles estimated on OCARINA are very reasonable.

Along-wind and crosswind components of the EC stress define the so-called stress angle $\theta=\tan ^{-1}\left(\overline{v^{\prime} w^{\prime}} / \overline{u^{\prime} w^{\prime}}\right)$. The angle $\theta$ was plotted versus the horizontal wind speed in Fig. 12. As shown in Fig. 12, the scatter is large if the wind speed is smaller than $6 \mathrm{~m} \mathrm{~s}^{-1}$. In contrast, if the wind speed is larger than $6 \mathrm{~m} \mathrm{~s}^{-1}$, then wind and stress are almost aligned with each other, which fits well with existing data (e.g., Grachev et al. 2001), in spite of the very limited number of points available for comparison.

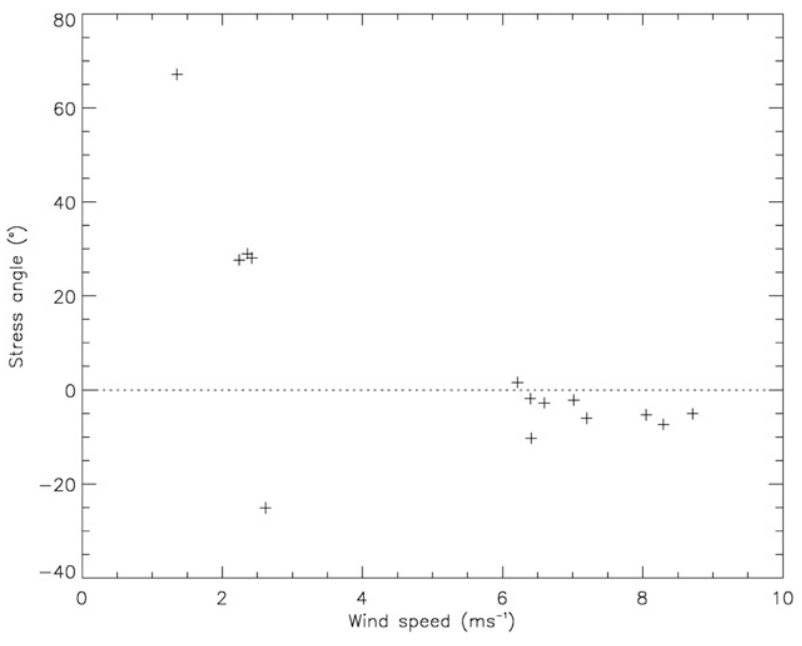

FIG. 12. Angle between the turbulent stress and the along-wind mean direction, as a function of the true wind speed.

\section{Wind-wave interaction}

In this section, we investigate the relation between the instantaneous horizontal wind modulus $U$ calculated with respect to the ground (as opposed to the wind relative to OCARINA) and $\eta$.

Eight cases are available for analysis, namely, four cases with wind and swell traveling in the same direction - that is, cases 7-10 in Table 2-and four cases when swells are traveling in the opposite direction to the winds-that is, cases 11-14 in Table 2. Each case corresponds to a time interval of $20 \mathrm{~min}$, which corresponds to 60000 samples.

First, we estimated the dominant wave period $T_{0}$ of the swell, as the inverse of the frequency $f_{0}$ that corresponded to the maximum of the power spectrum of $\eta$, over 20-min intervals. Next, the $f_{0}$ estimates were used to calculate the dominant wavelength $L_{\infty}$, the wavenumber $k$, and the phase speed of waves at the peak frequency $c$ using the linear wave dispersion relationship, with the hypotheses that wave amplitude $a$ is small and that water column is deep. Wave age $(c / U)$ and wave steepness $(a / k)$ were then calculated, the value of $a$ being approximated as $0.5 H$. The maximum of the orbital speed $\left(V_{\text {orb }}\right)_{\max }$, which is the value of the orbital speed at the crests of the waves, was finally estimated as

$$
\left(V_{\text {orb }}\right)_{\max }=\pi\left(H / T_{0}\right) \exp \left[\left(2 \pi / L_{\infty}\right) a\right]
$$

There could be significant differences between the calculated value of $\left(V_{\text {orb }}\right)_{\max }$ and its actual value, but unfortunately it was not possible to get a more direct estimate of it because no log instrument (which would 
a)

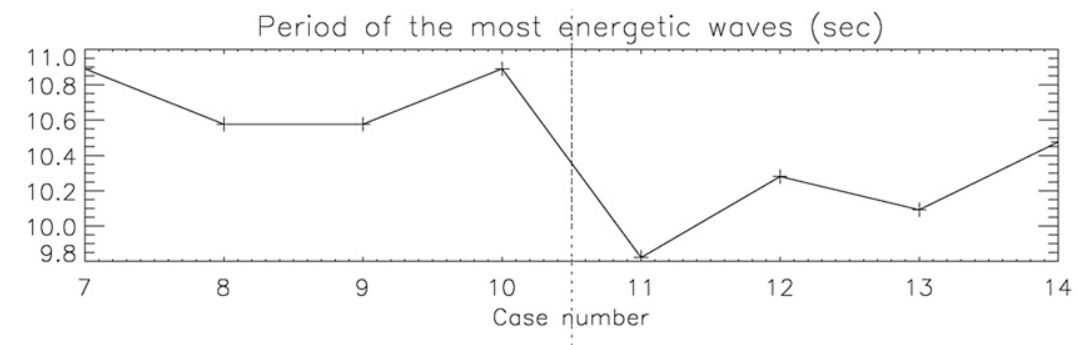

b)

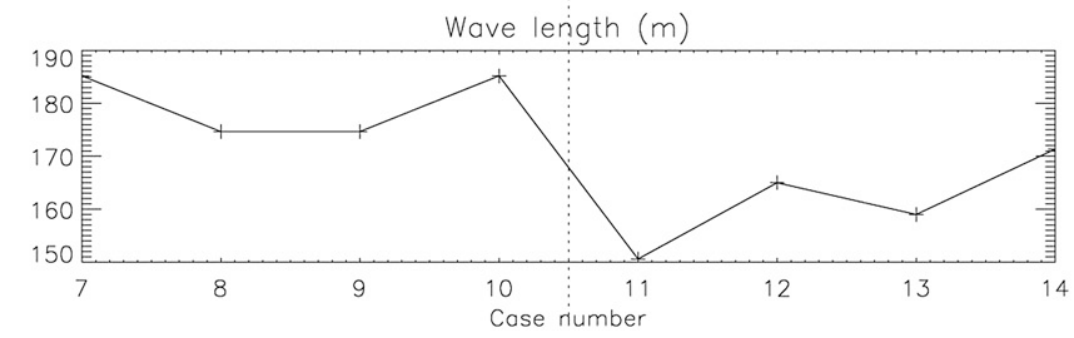

c)

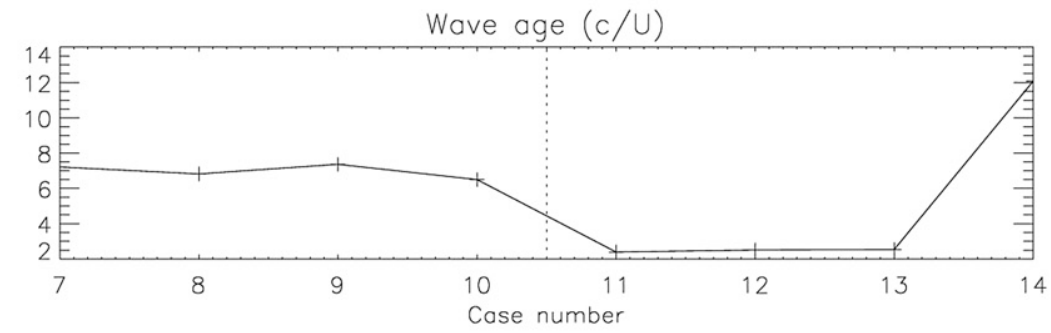

Wave steepness (a.k)

d)

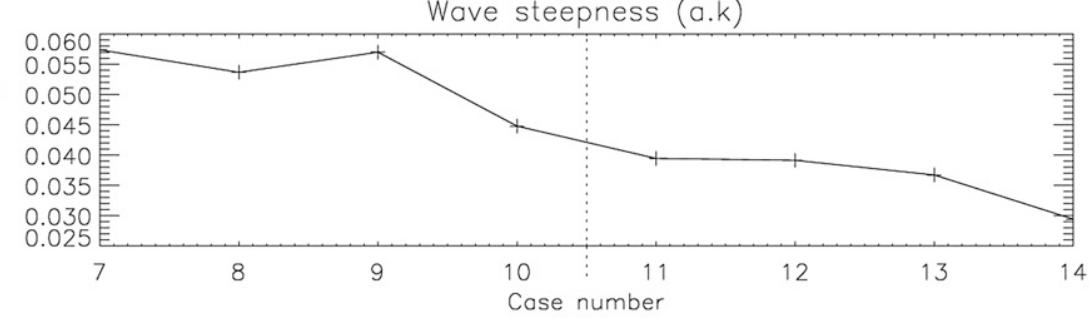

e)

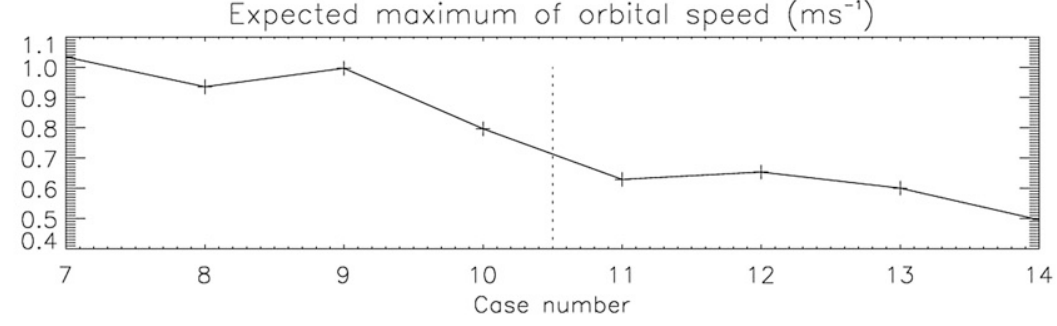

FIG. 13. Wave characteristics in open ocean conditions, during the FROMVAR experiment. On the $x$ axis, one graduation corresponds to one 20-min bin.

measure the speed of the platform with respect to the sea surface) was available on OCARINA during FROMVAR. The above-mentioned wave characteristics are summarized in Fig. 13.

The existence of a relationship between wind and waves was investigated by studying the spectral coherence coh and the phase $\varphi$ between $\eta$ and $U$. The values of coh and $\varphi$ were computed as

$$
\begin{aligned}
\operatorname{coh} & =\frac{\langle\operatorname{DFT}(U) \times \operatorname{conj}[\operatorname{DFT}(\eta)]\rangle^{2}}{\|\operatorname{DFT}(U)\|^{2} \times\|\operatorname{DFT}(\eta)\|^{2}} \text { and } \\
\varphi & =\operatorname{Arg}\left[\frac{\operatorname{DFT}(\eta)}{\operatorname{DFT}(U)}\right]
\end{aligned}
$$

where DFT is the discrete Fourier transform and the angle brackets $(\langle\rangle)$ operator denotes ensemble averaging. 
Eight spectra of coh and $\varphi$ are shown in Fig. 14, for example. To summarize the results for the eight cases, and to test the detection of the coherence between coh and $\varphi$, the mean value of coh was calculated in the spectral range of the swell (i.e., between 0.06 and $0.18 \mathrm{~Hz}$ for cases 7-10, and between 0.08 and $0.15 \mathrm{~Hz}$ for cases 11-14), and then it was divided by the standard deviation $\sigma_{f}$ of coh. As shown in Fig. 15a, coh is larger than $2 \sigma$ for each case, which means that it is meaningful to interpret the phase between $\eta$ and $U$ in the frequency range of the swell, as shown in Fig. $15 b$.

Cases $7-10$ present a phase shift of $3.0^{\circ}$ between wind and waves. For cases $11-14$, the average phase shift is even smaller - that is, $1.9^{\circ}$ - as can be checked in Fig. 15b. The phase shift $\varphi$ between $\eta$ and the wind relative to the waves, which is defined as $\mathbf{U}_{r}=\mathbf{U}-\mathbf{c}$, is best illustrated in Fig. 16, averaged over all cases. As shown in Fig. 16, the wind maximum occurs near the crest of the swell, but with a small phase shift on the side of the windward face. This could result from errors associated with the values of $\varphi$ given above. We expect that the correction of the motion of OCARINA (based on accelerometer and gyroscope data) is the most important source of error. To check the impact of this source of error on $\varphi$, we performed new calculations of $\varphi$ with a perturbation factor in the motion correction, in a ratio of $-30 \%$ to $+30 \%$, which is a worst-case scenario. The result was a shift of phase of $\pm 8^{\circ}$ to $13^{\circ}$. Surface current was taken into account in the calculation of $U$. We also checked the impact of an error on the value of the current. If the current is not taken into account, then the values of $\varphi$ are modified by $-1^{\circ}$ only; thus, current has little impact on the phase found. Finally, we found that the average value of $\varphi$ was $+2.4^{\circ} \pm 14^{\circ}$.

Since real waves are not pure monochromatic sinusoidal functions, it is difficult to illustrate the mean wind profile along the phase of the wave. Instead, we analyzed the statistical relation between $U$ and $\eta$. The time series of $U$ and $\eta$ were band filtered in the spectral region of maximum coherence, that is, between 0.06 and $0.18 \mathrm{~Hz}$ for cases 7-10, and between 0.08 and $0.15 \mathrm{~Hz}$ for cases 11-14. Next, the time series of $U$ and $\eta$ were normalized as $U_{n}(t)=U(t) / 4 \sigma_{U}$ and $\eta_{n}(t)=\eta(t) / 4 \sigma_{\eta}$, respectively, and then were shifted according to $\varphi$. Next, the correlation coefficient and the slope $\alpha$ of the first-degree linear fit between $U_{n}$ and $\eta_{n}$ were calculated. As shown in Fig. 17, there is a statistical linear relationship between $U_{n}$ and $\eta_{n}$, even though $\alpha$ varies by more than $50 \%$ depending on the case under consideration. Wind amplitude was estimated as $2 \sigma_{U}$. Its values are plotted in Fig. 17c. On average, we found that $2 \sigma_{U}=0.9 \mathrm{~m} \mathrm{~s}^{-1}$ for following-swell cases, and $2 \sigma_{U}=1.4 \mathrm{~m} \mathrm{~s}^{-1}$ for counterswell cases, which is comparable to the maximum orbital speed values represented in Fig. 13. This supports the idea that OCARINA is well adapted to further study the wave-induced wind undulation and stress.

\section{Discussion}

A new design of platform is proposed for determining air-sea turbulent fluxes, surface heat budget, and some aspects of wave characteristics. OCARINA design and the results found in the present paper with OCARINA data are discussed hereafter, despite only a limited test set of 14 cases was available for validating the use of the platform and for investigating wave characteristics, turbulent fluxes, and wind-wave interactions.

\section{a. Design}

It was observed that the platform motion characteristics were fully compatible with the determination of fluxes (section 4b). OCARINA orients itself perpendicular to the relative wind, which is not the best configuration for airflow distortion. However, distortion is still small, $\sim 3^{\circ}$, as was shown in section 4 a.

The proposed design is obviously not the only possible response to the design criteria mentioned in section 1 . Furthermore, the design is probably not better in terms of aerodynamic performance than what can be obtained by the ASIS buoy (Graber et al. 2000), at least for measurements performed at heights larger than $1.5 \mathrm{~m}$.

With the chosen configuration, the three main following criticisms can be made. First, a host ship is still required to deploy and recover the platform. Second, it would be impossible to get time series longer than a day with no gaps because batteries would have to be charged after $12 \mathrm{~h}$. Last, a light design means a very limited payload and electric power; thus, the range of instruments that can be installed on OCARINA is limited. Electric power would be even more limited in cold regions, where batteries would be less efficient. On the contrary, OCARINA was recently tested with success in tropical regions, with no overheating issues.

Wave heights for wavelengths larger than the size of the platform could be inferred from the motion of the platform with reasonable accuracy, on the order of $0.1 \mathrm{~m}$ in rms. However, as opposed to systems like ASIS, OCARINA cannot currently sample short waves. In addition, directional spectra of waves (hodographs) are presently not available. Note that ancillary gauges could be installed for obtaining these data, in the future.

Another limitation of OCARINA is that it drifts rather quickly under the effects of wind and surface current $\left(<0.5 \mathrm{~m} \mathrm{~s}^{-1}\right.$ drift in a 10-kt wind). Drift is an issue that must be taken into account while planning the mission of the host ship, or if obstacles are present, as in 


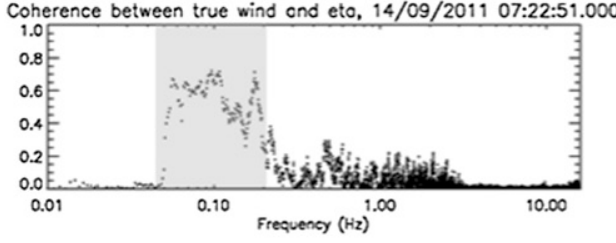

Coherence between true wind and eto, 14/09/2011 07:41:11.000

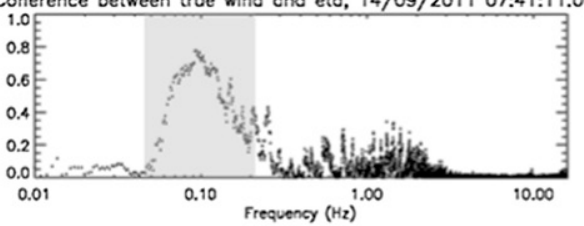

Coherence between true wind ond eto, 14/09/2011 07:59:31.000

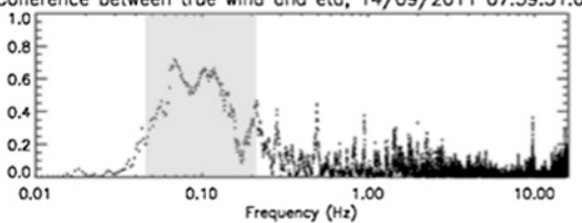

Coherence between true wind and eto, 14/09/2011 17:09:31.000

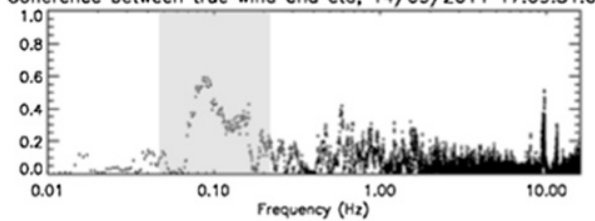

Coherence between true wind and eto, 15/09/2011 08:13:57.000

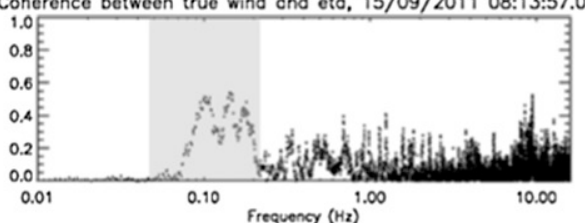

Coherence between true wind ond eto, 15/09/2011 08:32:17.000

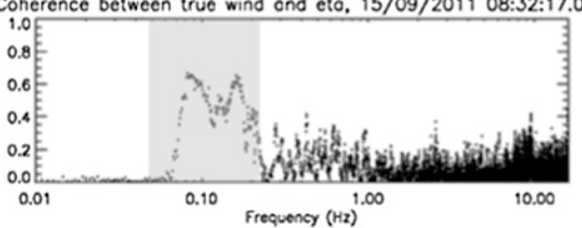

Coherence between true wind ond eto, 15/09/2011 09:27:17.000
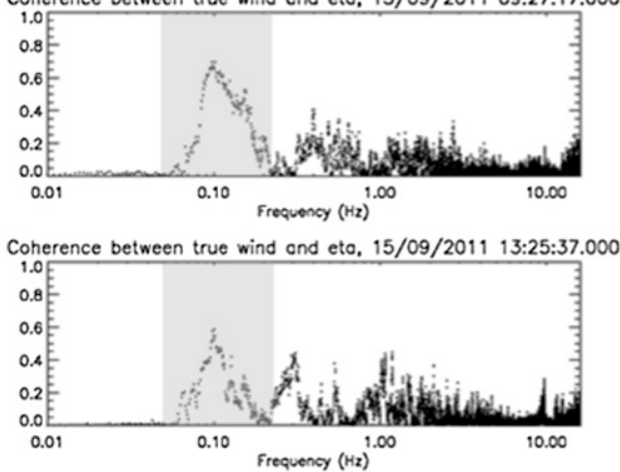

Case 7

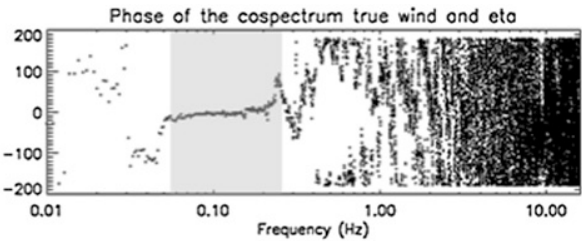

Case 8

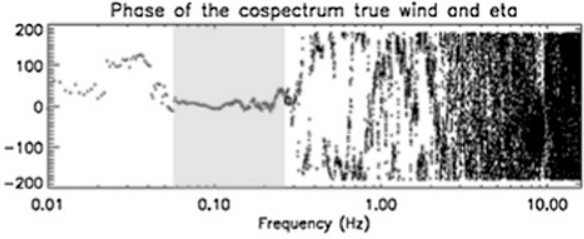

Case 9

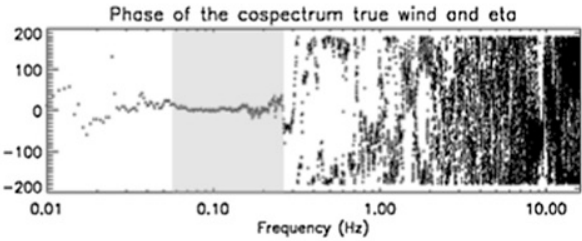

Case 10

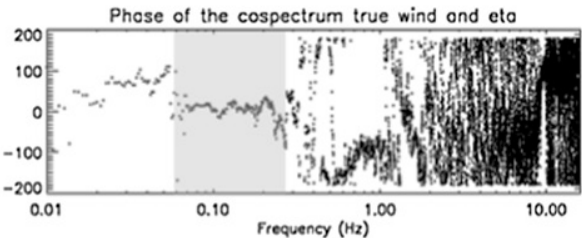

Case 11

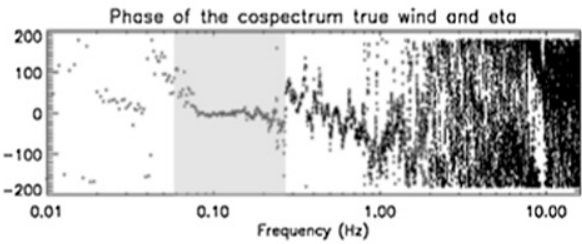

Case 12

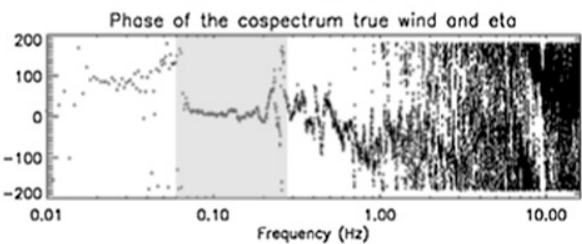

Case 13

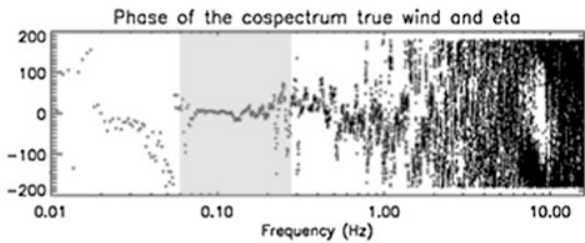

Case 14

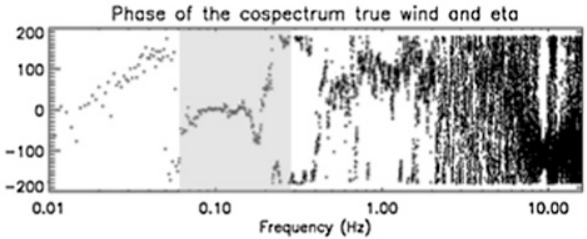

FIG. 14. Spectra of (left) coherence and (right) phase between wind and sea surface elevation (eta). The gray-shaded areas highlight the spectral regions of the swell, where the coherence is the largest. Phases are expressed in degrees. Each spectrum is calculated on a 20-min interval that starts at the time indicated in the panel title. 

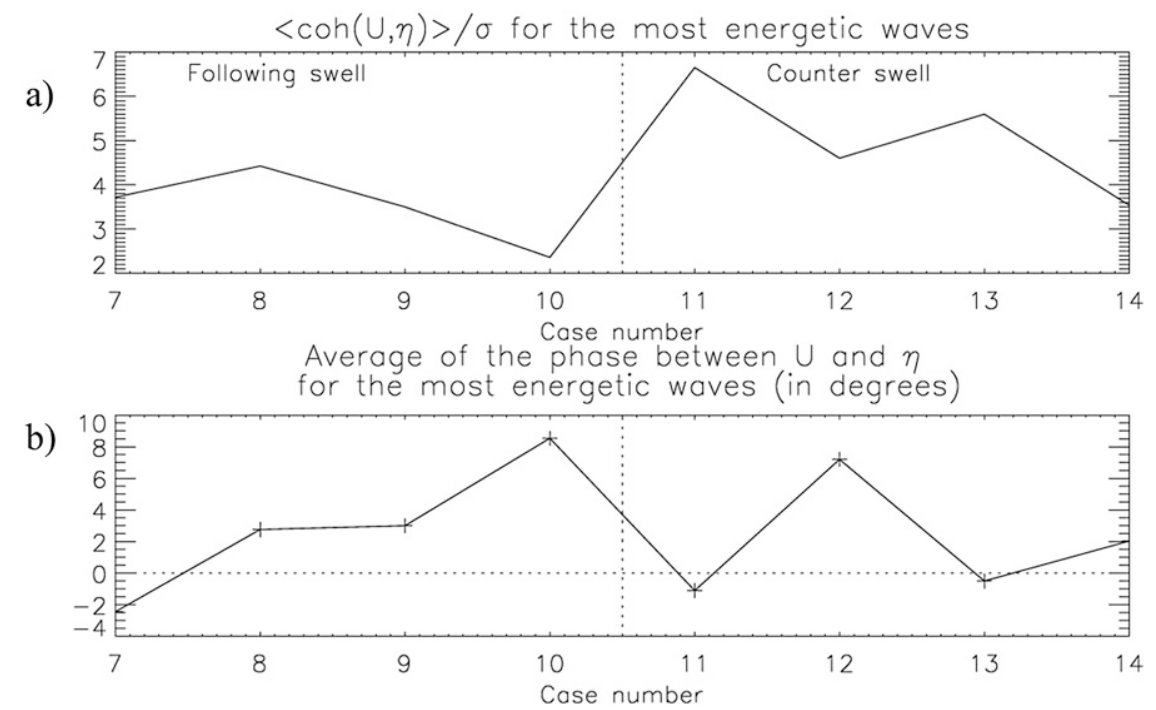

FIG. 15. Detection of (a) coherence between $U$ and $\eta$ for the spectral region of the swell and (b) phase between $U$ and $\eta$. In (a), the coherence between $U$ and $\eta$ is detected because the values are larger than 2 for all cases.

coastal areas. Adding a drogue (parachute) to limit the drift of OCARINA was not attempted, as it could affect the motion of OCARINA and thus the quality of the wave height estimates.

While designing OCARINA, a major concern was water intrusion on the instruments so close to the waves. Water could affect the quality of sonic anemometer and radiation data. In practice, this did not happen for winds up to $17 \mathrm{kt}$ (recorded in the Bay of Douarnenez at the beginning of the FROMVAR experiment) and for waves up to $3.3 \mathrm{~m}$ (on 14 September 2011, during FROMVAR), possibly due to its light weight, its stability, its small size, and the subsequent constant height of the instruments above water. However, this could be problematic for steep waves and large spray generation. No simulation was made to further assess the maximum acceptable wave steepness or height that OCARINA could withstand.

\section{b. Air-sea fluxes}

Four flux estimation methods were applied, namely, the EC method, the ID method, the bulk method, and the profile method (for $u^{*}$ only). Only the friction velocity and the buoyancy flux were discussed in the present paper, as no instrument was available for measuring humidity fluctuations during the experiment. Cospectra of $u^{\prime} w^{\prime}$ exhibited similar behavior as the empirical model of Kaimal et al. (1972) for cases of unstable surface boundary layer. However, in the lower-frequency range, OCARINA cospectra were higher than those of the model. In addition, it was noticed that the comparisons between EC $u^{*}$ estimates and bulk and ID $u^{*}$ estimates were improved by a factor up to 2 if the lower parts of the spectra were filtered out in the EC method, with a cutoff time period of $35 \mathrm{~s}$. Under stable conditions or in low wind conditions, the OCARINA cospectra of $u^{\prime} w^{\prime}$ were significantly different from the Kaimal et al. (1972) model, although the corresponding $u^{*}$ estimates were in good agreement with the other methods.

As OCARINA is a wave follower, the EC $u^{*}$ values measured at constant height above the surface could slightly differ from the EC $u^{*}$ values that would have been be measured at constant altitude [see the relationship

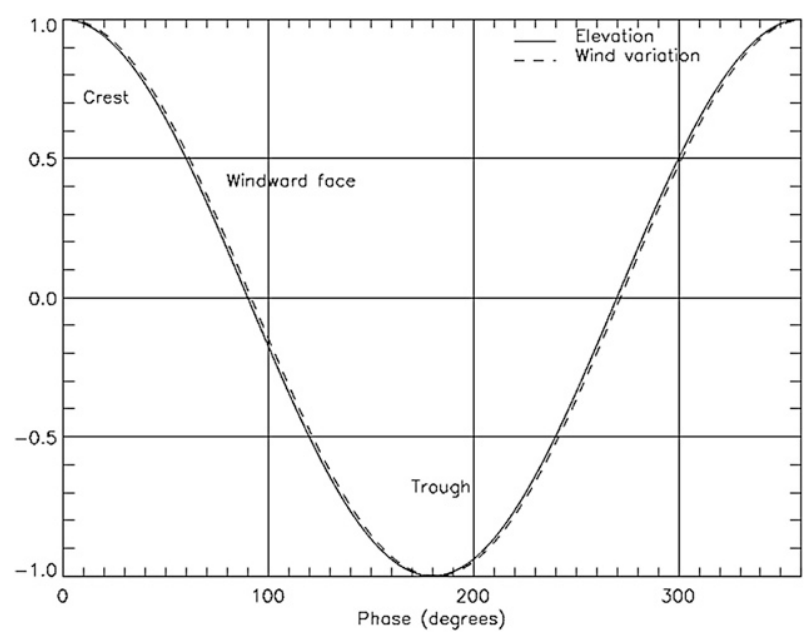

FIG. 16. Phase shift between wave and phase-averaged wind speed over cases 7-14. 
a)

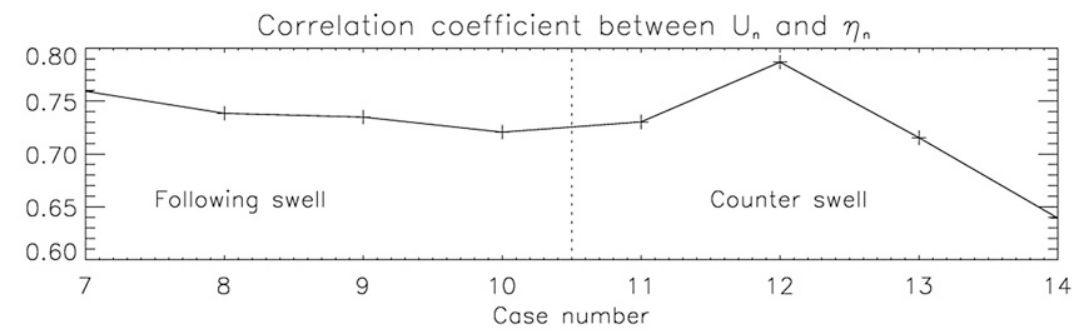

b)

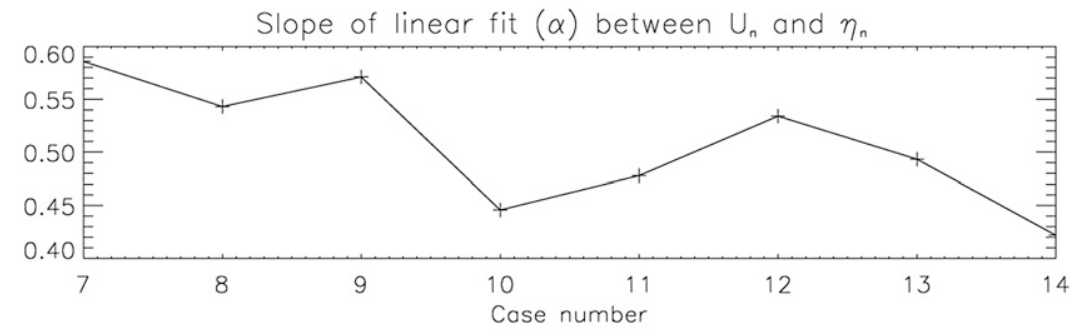

c)

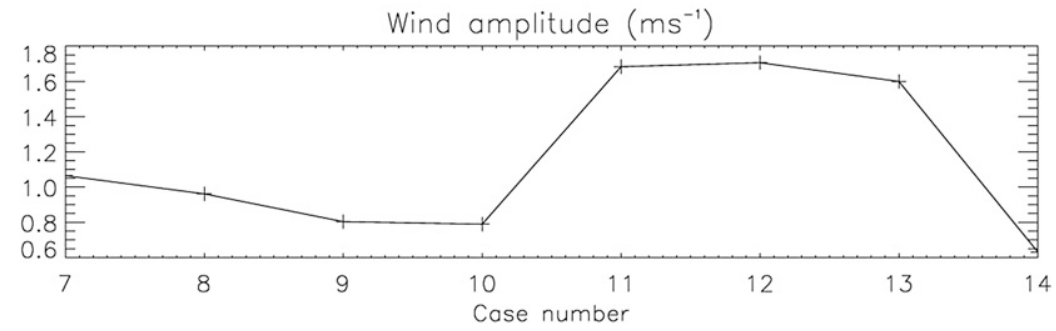

FIG. 17. Statistical elements of the relation between normalized (a),(b) $U_{n}$ and $\eta_{n}$ and (c) wind amplitude.

in Grare et al. (2013), appendix A]. The order of magnitude of the differences will be checked in a future work.

We found that the bulk buoyancy flux compared well to EC estimates of the flux. In contrast, the buoyancy flux estimates from the ID method did not have a good fit to EC fluxes or bulk fluxes, especially in stable conditions. Unfortunately, too few points of comparison were available to draw firm conclusions. In a future work, this issue will be further investigated. The exponents of the inertial ranges of wind and temperature spectra, the critical Richardson number, and $z$-less parameterization will be tested and compared to recent results of Grachev et al. (2012).

\section{c. Wind and waves}

It was shown that the alignment between stress and the mean wind direction was good when the wind speed was larger than $6 \mathrm{~m} \mathrm{~s}^{-1}$, which is consistent with earlier results (Grachev et al. 2001). Wind and swell were spectrally coherent for eight cases. Furthermore, statistical linear relationships were found between wind variations and surface elevation. The phase shift between wind and swell was $+2.4^{\circ} \pm 14^{\circ}$ (average of followingand counterswell cases). Currently, there is a lack of data showing the phase between wind and surface elevation in the open sea. However, numerical models have been run (e.g., Sullivan et al. 2008), and wind tunnel data (Grare et al. 2013) as well as theoretical models (Kudryavtsev et al. 2001; Semedo et al. 2009) were already published on the subject. According to the simulations made by Sullivan et al. (2008, p. 1231, their Fig. 5 ), wind should be in phase with the elevation, that is, wind accelerates on wave crests and slows down in wave troughs, consistent with what was found for OCARINA. Following previous authors (Belcher and Hunt 1993; Cohen and Belcher 1999), a model of airflow above waves was proposed by Kudryavtsev et al. (2001), in which the atmospheric layer was split into two regions, the inner and the outer regions. The altitude $l$ of the limit separating both regions was defined by the following expression:

$$
k l=\frac{2 \kappa u^{*}}{|U(l)|} .
$$

According to OCARINA data, the value of $l$ is $\sim 0.9 \mathrm{~m}$, which means that OCARINA data at $1.5 \mathrm{~m}$ are made at the bottom of the outer region. According to the simulations and to the validation data of Kudryavtsev et al. 
(2001) as well as Sullivan et al. (2008), wind would be smaller in the trough of the waves than over the crests, which is in qualitative agreement with the present data. However, one would expect a larger phase shift value, that is, wind would be at maximum on the windward sides of the waves-in advance with respect to the crest. The phase would also increase with wave steepness, and decrease with wave age (Grare et al. 2013). In the present paper, wave age is large, that is, $2-12$, and wave steepness is rather small, from 0.03 to 0.06 , which might explain the small value of the phases found. No clear relationship was found between wind amplitude and orbital velocity, although they are of compatible magnitude.

An effort to add a humidity fluctuation measurement instrument, a log, and a set of wave gauges to OCARINA is in progress. In its present configuration, OCARINA was recently deployed during the Salinity Processes in the Upper Ocean Regional Study (SPURS) Subtropical Atlantic Surface Salinity Experiment (STRASSE) (e.g., Reverdin et al. 2013), providing $120 \mathrm{~h}$ for data collection. Data processing and analysis are ongoing at Laboratoire Atmosphères, Milieux, Observations Spatiales (LATMOS), and will be the object of a future paper. The masts of OCARINA will be adapted to a wave glider in the near future (http://liquidr.com).

Acknowledgments. The authors are grateful to the captains and the crew of the INSU R/V Côtes de la Manche, DT of INSU at la Seyne sur Mer, B. Zucchini at IRPHE, and F. Rémy at Ecole Centrale de Marseille for their help. The development of OCARINA was funded by several sources that included IPSL, UPMCEMERGENCE, and LATMOS.

\section{REFERENCES}

Anctil, F., M. A. Donelan, W. M. Drennan, and H. C. Graber, 1994: Eddy-correlation measurements of air-sea fluxes from a discus buoy. J. Atmos. Oceanic Technol., 11, 1144-1150, doi:10.1175/ 1520-0426(1994)011<1144:ECMOAS>2.0.CO;2.

Belcher, S. E., and J. C. R. Hunt, 1993: Turbulent shear flow over slowly moving waves. J. Fluid Mech., 251, 109-148, doi:10.1017/ S0022112093003350.

Berry, D. I., E. C. Kent, and P. K. Taylor, 2004: An analytical model of heating errors in marine air temperatures from ships. J. Atmos. Oceanic Technol., 21, 1198-1215, doi:10.1175/ 1520-0426(2004)021<1198:AAMOHE > 2.0.CO;2.

Bourras, D., and Coauthors, 2009: Turbulent air-sea fluxes in the Gulf of Guinea during the AMMA experiment. J. Geophys. Res., 114, C04014, doi:10.1029/2008JC004951.

Brut, A., A. Butet, P. Durand, G. Caniaux, and S. Planton, 2005: Airsea exchanges in the equatorial area from the EQUALANT99 dataset: Bulk parameterizations of turbulent fluxes corrected for airflow distortion. Quart. J. Roy. Meteor. Soc., 131, $2497-$ 2538, doi:10.1256/qj.03.185
Christensen, K. H., J. Röhrs, B. Ward, I. Fer, G. Broström, O. Saetra, and O. Breivik, 2013: Surface wave measurements using a ship-mounted ultrasonic altimeter. Methods Oceanogr., 6, 1-15, doi:10.1016/j.mio.2013.07.002.

Cohen, J. E., and S. E. Belcher, 1999: Turbulent shear flow over fast-moving waves. J. Fluid Mech., 386, 345-371, doi:10.1017/ S0022112099004383.

Donelan, M. A., F. W. Dobson, S. D. Smith, and R. J. Anderson, 1993: On the dependence of sea surface roughness on wave development. J. Phys. Oceanogr., 23, 2143-2149, doi:10.1175/ 1520-0485(1993)023<2143:OTDOSS > 2.0.CO;2.

— W. M. Drennan, and K. B. Katsaros, 1997: The air-sea momentum flux in conditions of wind sea and swell. J. Phys. Oceanogr., 27, 2087-2099, doi:10.1175/1520-0485(1997)027<2087: TASMFI $>2.0 . \mathrm{CO} ; 2$.

- A. V. Babanin, I. R. Young, M. L. Banner, and C. McCormick, 2005: Wave-follower field measurements of the wind-input spectral function. Part I: Measurements and calibrations. J. Atmos. Oceanic Technol., 22, 799-813, doi:10.1175/JTECH1725.1.

Dupuis, H., P. K. Taylor, A. Weill, and K. Katsaros, 1997: Inertial dissipation method applied to derive turbulent fluxes over the ocean during the Surface of the Ocean, Fluxes and Interactions with the Atmosphere/Atlantic Stratocumulus Transition Experiment (SOFIA/ASTEX) and Structure des Echanges Mer-Atmosphere, Proprietes des Heterogeneites Oceaniques: Recherche Experimentale (SEMAPHORE) experiments with low to moderate wind speeds. J. Geophys. Res., 102, 21115-21 129, doi:10.1029/97JC00446.

Edson, J. B., C. W. Fairall, P. G. Mestayer, and S. E. Larsen, 1991: A study of the inertial-dissipation method for computing airsea fluxes. J. Geophys. Res., 96, 10689-10711, doi:10.1029/ 91JC00886.

, A. A. Hinton, K. E. Prada, J. E. Hare, and C. W. Fairall, 1998: Direct covariance flux estimates from mobile platforms at sea. J. Atmos. Oceanic Technol., 15, 547-562, doi:10.1175/ 1520-0426(1998)015<0547:DCFEFM > 2.0.CO;2.

— , and Coauthors, 2007: The Coupled Boundary Layers and Air-Sea Transfer experiment in low winds. Bull. Amer. Meteor. Soc., 88, 341-356, doi:10.1175/BAMS-88-3-341.

Fairall, C. W., E. F. Bradley, J. E. Hare, A. A. Grachev, and J. B. Edson, 2003: Bulk parameterization of air-sea fluxes: Updates and verification for the COARE algorithm. J. Climate, 16, 571-591, doi:10.1175/1520-0442(2003)016<0571:BPOASF $>2.0 . C O ; 2$.

Graber, H. C., E. A. Terray, M. A. Donelan, W. M. Drennan, J. C. Van Leer, and D. B. Peters, 2000: ASIS-A new AirSea Interaction Spar buoy: Design and performance at sea. J. Atmos. Oceanic Technol., 17, 708-720, doi:10.1175/ 1520-0426(2000)017<0708:AANASI >2.0.CO;2.

Grachev, A. A., C. W. Fairall, J. E. Hare, and J. B. Edson, 2001: Wind stress over sea waves. Preprints, 11th Conf. on Interaction of the Sea and Atmosphere, San Diego, CA, Amer. Meteor. Soc., 1.4. [Available online at https://ams.confex.com/ ams/Polar-AirSe/webprogram/Paper20171.html.]

, E. L. Andreas, C. W. Fairall, P. S. Guest, and P. O. G. Persson, 2012: The critical Richardson number and limit of applicability of Monin-Obukhov similarity theory in the stable atmospheric boundary layer. Preprints, 20th Symp. on Boundary Layers and Turbulence, Boston, MA, Amer. Meteor. Soc., 3B.5. [Available online at https://ams.confex.com/ ams/20BLT18AirSea/webprogram/Paper209287.html.]

Grare, L., W. L. Peirson, H. Branger, J. W. Walker, J.-P. Giovanangeli, and V. Makin, 2013: Growth and dissipation of wind-forced deepwater waves. J. Fluid Mech., 722, 5-50, doi:10.1017/jfm.2013.88. 
Howden, S., D. Gilhousen, N. Guinasso, J. Walpert, M. Sturgeon, L. Bender, 2008: Hurricane Katrina winds measured by a buoy-mounted sonic anemometer. J. Atmos. Oceanic Technol., 25, 607-616, doi:10.1175/2007JTECHO518.1.

Kaimal, J. C., J. C. Wyngaard, Y. Izumi, and O. R. Coté, 1972: Spectral characteristics of surface-layer turbulence. Quart. J. Roy. Meteor. Soc., 98, 563-589, doi:10.1002/qj.49709841707.

Katsaros, K. B., 1980: The aqueous thermal boundary layer. Bound.-Layer Meteor., 18, 107-127, doi:10.1007/BF00117914.

— M. A. Donelan, and W. M. Drennan, 1993: Flux measurements from a SWATH ship in SWADE. J. Mar. Syst., 4, 117132, doi:10.1016/0924-7963(93)90003-5.

Kolmogorov, A. N., 1941: The local structure of turbulence in incompressible viscous fluid for very large Reynolds numbers. Izv. Acad. Sci. USSR, 30, 299-303.

Kudryavtsev, V. N., V. K. Makin, and J. F. Meirink, 2001: Simplified model of the air flow above waves. Bound.-Layer Meteor., 100, 63-90, doi:10.1023/A:1018914113697.

Le Boyer, C., G. Cambon, N. Daniault, S. Herbette, B. Le Cann, L. Marié, P. Morin, 2009: Observations of the Ushant tidal front in September 2007. Cont. Shelf Res., 29, 1026-1037, doi:10.1016/j.csr.2008.12.020.

Lecornu, F., and Y.-H. De Roeck, 2009: PREVIMER-Coastal observations and forecasts. Houille Blanche, 1, 60-63, doi:10.1051/lhb:2009006.

Liu, W. T., K. B. Katsaros, and J. A. Businger, 1979: Bulk parameterization of air-sea exchanges of heat and water vapor including the molecular constraints at the interface. J. Atmos. Sci., 36, 1722-1735, doi:10.1175/1520-0469(1979)036<1722: BPOASE $>2.0 . \mathrm{CO} ; 2$.

Miller, S. D., T. S. Hristov, J. B. Edson, and C. A. Friehe, 2008: Platform motion effects on measurements of turbulence and air-sea exchange over the open ocean. J. Atmos. Oceanic Technol., 25, 1683-1694, doi:10.1175/2008JTECHO547.1.

Monin, A. S., and A. M. Obukhov, 1954: Basic laws of turbulent mixing in the surface layer of the atmosphere. Tr. Geofiz. Inst., Akad. Nauk SSSR, 24, 163-187.

Morisset, S., and G. Reverdin, 2011: Prototype drifter study: “Tag proto" (SMRULOCEAN). LOCEAN-UMPC Internal Rep., $38 \mathrm{pp}$.

Pedreros, R., G. Dardier, H. Dupuis, H. C. Graber, W. M. Drennan, A. Weill, C. Guérin, and P. Nacass, 2003: Momentum and heat fluxes via the eddy correlation method on the R/V L'Atalante and an ASIS buoy. J. Geophys. Res., 108, 3339, doi:10.1029/ 2002JC001449.
Popinet, S., M. Smith, and C. Stevens, 2004: Experimental and numerical study of the turbulence characteristics of airflow around a research vessel. J. Atmos. Oceanic Technol., 21, 1575-1589, doi:10.1175/1520-0426(2004)021<1575:EANSOT>2.0.CO;2.

Reverdin, G., and Coauthors, 2013: Surpact: A SMOS surface drifter for air-sea interaction. Oceanography, 26, 48-56, doi:10.5670/ oceanog.2013.04.

Sahlée, E., W. M. Drennan, H. Potter, and M. A. Rebozo, 2012: Waves and air-sea fluxes from a drifting ASIS buoy during the Southern Ocean Gas Exchange experiment. J. Geophys. Res., 117, C08003, doi:10.1029/2012JC008032.

Semedo, A., Ø. Saetra, A. Rutgersson, K. K. Kahma, and H. Pettersson, 2009: Wave-induced wind in the marine boundary layer. J. Atmos. Sci., 66, 2256-2271, doi:10.1175/2009JAS3018.1.

Smedman, A., U. Högström, E. Sahleé, W. M. Drennan, K. K. Kahma, H. Pettersson, and F. Zhang, 2009: Observational study of marine atmospheric boundary layer characteristics during swell. J. Atmos. Sci., 66, 2747-2763, doi:10.1175/ 2009JAS2952.1.

Smith, S. D., 1988: Coefficients for sea surface wind stress, heat flux, and wind profiles as a function of wind speed and temperature. J. Geophys. Res., 93, 15467-15472, doi:10.1029/ JC093iC12p15467.

Soloviev, Y. P., and V. N. Kudryavtsev, 2010: Wind-speed undulations over swell: Field experiment and interpretation. Bound.-Layer Meteor., 136, 341-363, doi:10.1007/s10546-010-9506-z.

Sullivan, P. P., J. B. Edson, T. Hristov, and J. C. McWilliams, 2008: Large-eddy simulations and observations of atmospheric marine boundary layers above nonequilibrium surface waves. J. Atmos. Sci., 65, 1225-1245, doi:10.1175/ 2007JAS2427.1.

Weill, A., and Coauthors, 2003: Toward a better determination of turbulent air-sea fluxes from several experiments. J. Climate, 16, 600-618, doi:10.1175/1520-0442(2003)016<0600: TABDOT $>2.0 . \mathrm{CO} ; 2$.

Weller, R. A., S. P. Bigorre, J. L. Jonathan, D. Ware, and J. B. Edson, 2012: A surface mooring for air-sea interaction research in the Gulf Stream. Part I: Mooring design and instrumentation. J. Atmos. Oceanic Technol., 29, 1363-1376, doi:10.1175/ JTECH-D-12-00060.1.

Yelland, M. J., B. I. Moat, R. W. Pascal, and D. I. Berry, 2002: CFD model estimates of the airflow distortion over research ships and the impact on momentum flux measurements. J. Atmos. Oceanic Technol., 19, 1477-1499, doi:10.1175/1520-0426(2002) 019<1477:CMEOTA > 2.0.CO;2. 